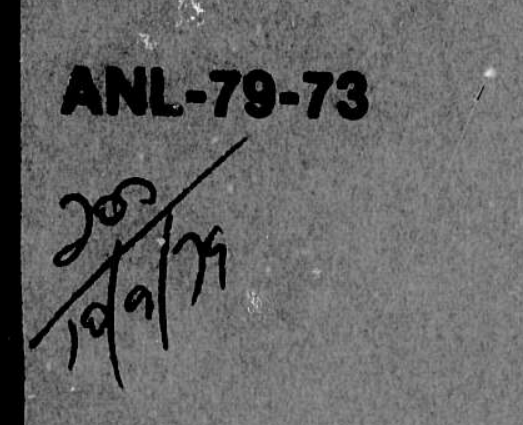

A. 133

ANL-79-73

MASTER

\title{
MULTICHANNEL CLAD-RELOCATION MODEL FOR FAST-REACTOR LOSS-OF-FLOW ACCIDENTS
}

by

M. Ishil, W. L. Chen, and M. A. Grolmes

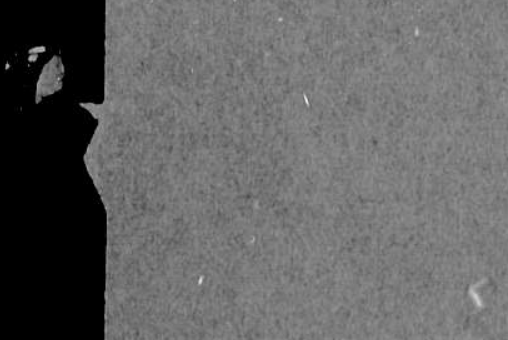

$i^{2}$

BASE TECHNOLOOY

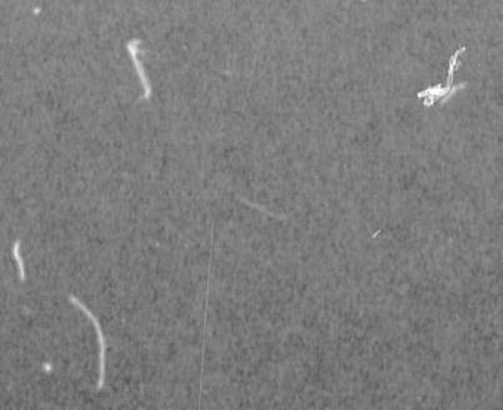

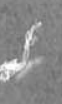

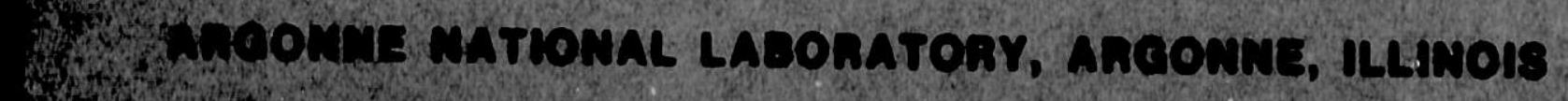

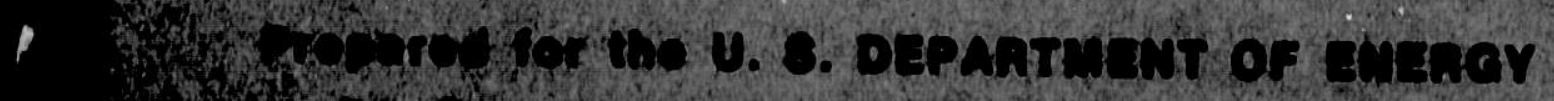

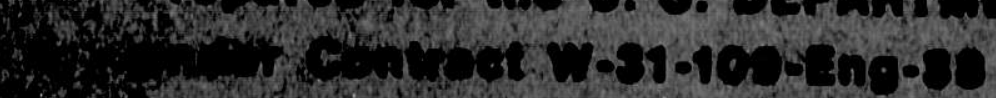

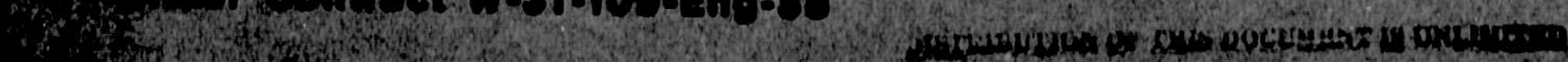
t. 
The facilities of Argonne National Laboratory are owned by the United States Government. Under the terms of a contract (W-31-109-Eng-38) among the U. S. Department of Energy, Argonne Universities Association and The University of Chicago, the University employs the staff and operates the Laboratory in accordance vith policies and programs formulated, approved and reviewed by the Association.

\section{MEMBERS OF ARGONNE UNIVERSITIES ASSOCIATION}

The University of Arizona Carnegie-Mellon University Case Western Reserve University The University of Chicago University of Cincinnati Illinois Institute of Technology

University of Illinois Indiana University The University of Iowa Iowa State University
The University of Kansas Kansas State University Loyola University of Chicago Marquette University The University of Michigan Michigan State University University of Minnesota University of Missouri Northwestern University University of Notre Dame
The Ohio State University

Ohio University

The Pennsylvania State University

Purdue University

Saint Louis University

Southern Illinois University

The University of Texas at Austin

Washington University

Wayne State University

The University of Wisconsin-Madison

\section{NOTICE}

This report was prepared as an account of work sponsored by an agency of the United States Government. Neither the United States nor any agency thereof, nor any of their employees, makes any warranty, expressed or implied, or assumes any legal liability or responsibility for any third party's use or the results of such use of any information, apparatus, product or process disclosed in this report, or represents that its use by such third party would not infringe privately owned rights. Mention of commercial products, their manufacturers, or their suppliers in this publication does not imply or connote approval or disapproval of the product by Argonne National Laboratory or the United States Government.

Printed in the United States of America

Available from

National Technical Information Service

U. S. Department of Commerce

S285 Port Royal Road

Springfield, VA 22161

1

NTIS price codes

Printed copy: A04

Microfiche copy: AOt 
Distribution Category:

LMFBR - Reactor Safety

$(\mathrm{UC}-79 \mathrm{p})$

ANL-79-73

ARGONNE NATIONAL LABORATORY

9700 South Cass Avenue

Argonne, Illino is 60439

MULTICHANNEL CLAD-RELOCATION MODEL FOR FAST-REACTOR LOSS-OF-FLOW ACCIDENTS

by

M. Ishii, W. L. Chen, and M. A. Grolmes

Reactor Analysis and Safety Division

August 1979

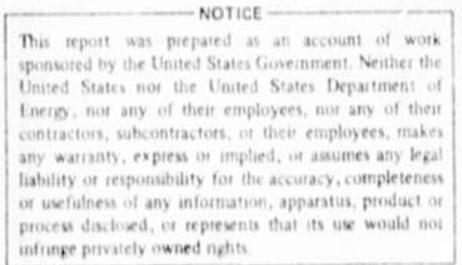






\section{Page}

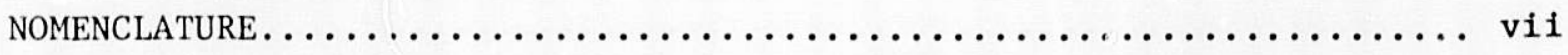

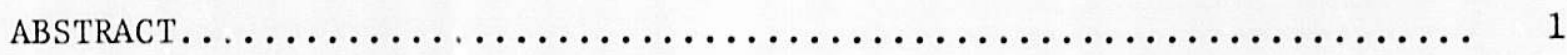

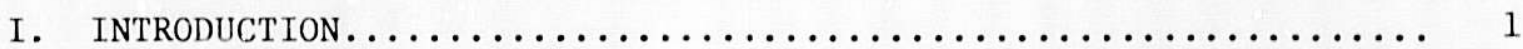

II. DESCRIPTION OF THE SYSTEM.......................... 4

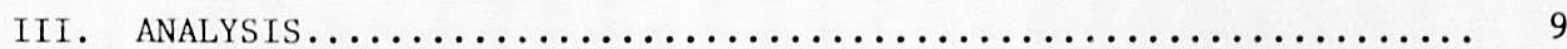

A. Basic Film Motion.............................. 9

B. Upper Freezing............................. 16

C. Transient Flooding and Deflooding................... 24

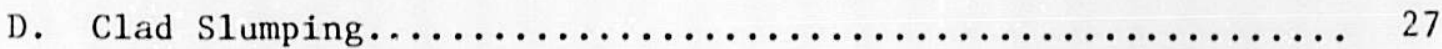

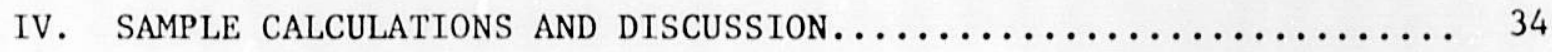

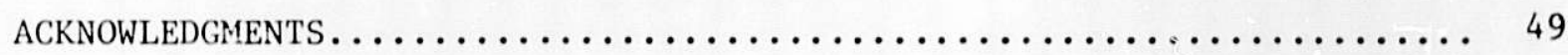

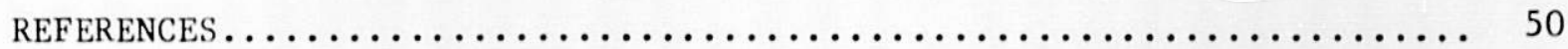


1. Cross Section of LMFBR Subassembly Typical of FFTF and CRBR..... 4

2. Typical Subchannel in th $^{\text {th }}$ Channe1.................... 5

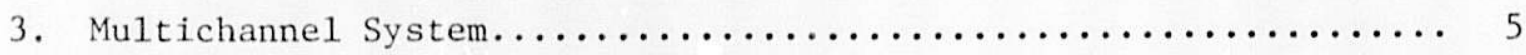

4. Positions of Melt Front and Liquid Film............... 15

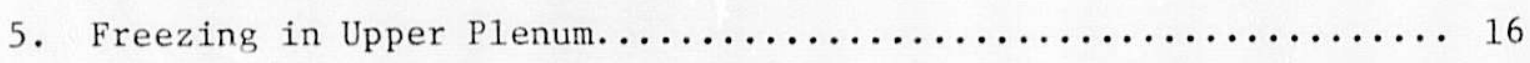

6. Upper Freezing $\ldots \ldots \ldots \ldots \ldots \ldots \ldots \ldots \ldots \ldots \ldots \ldots \ldots \ldots \ldots \ldots \ldots \ldots \ldots \ldots$

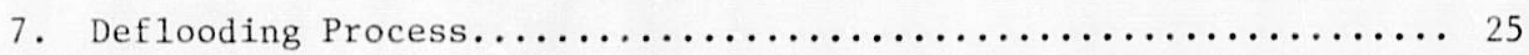

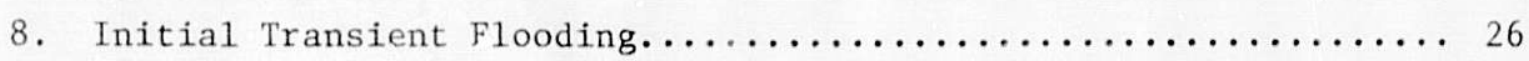

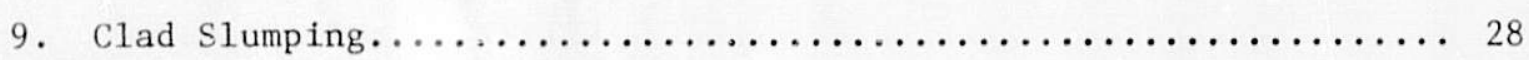

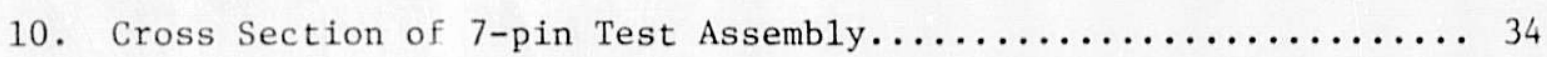

11. Post-transient Radiographs for $\mathrm{R}-4$ and $\mathrm{R}-5$ Loss-of-flow Tests... 35

12. Prediction of Molten-clad Velocity for Test R-5 Case with 2-channel Model Based on a Simple Voiding Mode1............ 37

13. Prediction of Molten-clad Motion for Test R-5 Case with 2-channel Model........................... 37

14. Prediction of Molten-clad Velocity for Test R-5 Case with Single-channel Model Based on Simple Voiding Mode1.......... 42

15. Prediction of Molten-clad Motion for R-5 Test Case with Single-channel Model Based on Simple Voiding Mode1......... 42

16. Effect on the Voiding and Fuel-pin Transient Model on the One-dimensional Clad Motion.................... 43

17. Effect of the Voiding and Fuel-pin Transient Model on Molten Clad Velocity........................... 43

18. Effect of Subassembly Incoherency Caused by Power Skew of Molten-clad Velocities Predicted by Using Three

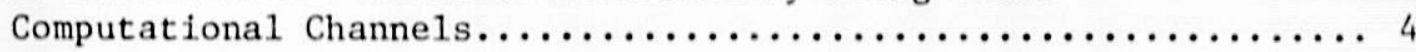

19. Effect of Power Skew on Molten-clad Motion and Blockage Formation................................. 44

20. Diversions of Sodium-vapor Fiow Caused by Nonuniform Melting Pattern of cladding............................ 44 


\section{LIST OF FIGURES (Cont'd)}

No.

21. Experimental Data on the Boiling Front Propagation for P3A Test...

22. Clad Motion Predictions from MULCLAD for P3A Loss-of-Flow

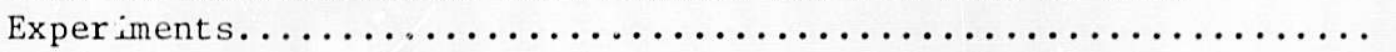

LIST OF TABLES

No.

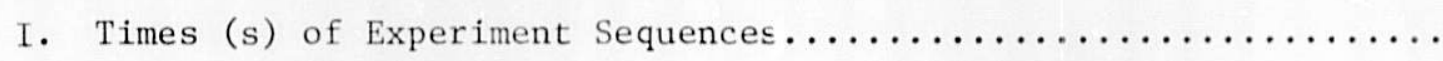


total flow area of intact $j$ th channel

a parameter given by Eq. (20)

a parameter given by Eq. (41)

molten-clad flow area per channel

vapor flow area per channel

flow area without cladding

specific heat of cladding

hydraulic diameter for the flow

shortest distance between fuel pins

wall friction factor for the cladding

latent heat of the cladding

length of subassembly film section

length of heated section

length of reflector

upper level at the end of fuel pins

equivalent number of fuel pins total area available for cladding accumulation

structural parameter given by Eq. (26)

hydraulic diameter for the sodium vapor

hydraulic diameter for the original channel

friction factor for the vapor phase based on $D_{o j}$

thermal conductivity of the cladding

blockage resistance coefficient given by Eq. (25)

length of the insulator or axial blanket

loss of vapor momentum due to flow diversion

mass used for bottom blockage from jth-channel film mass

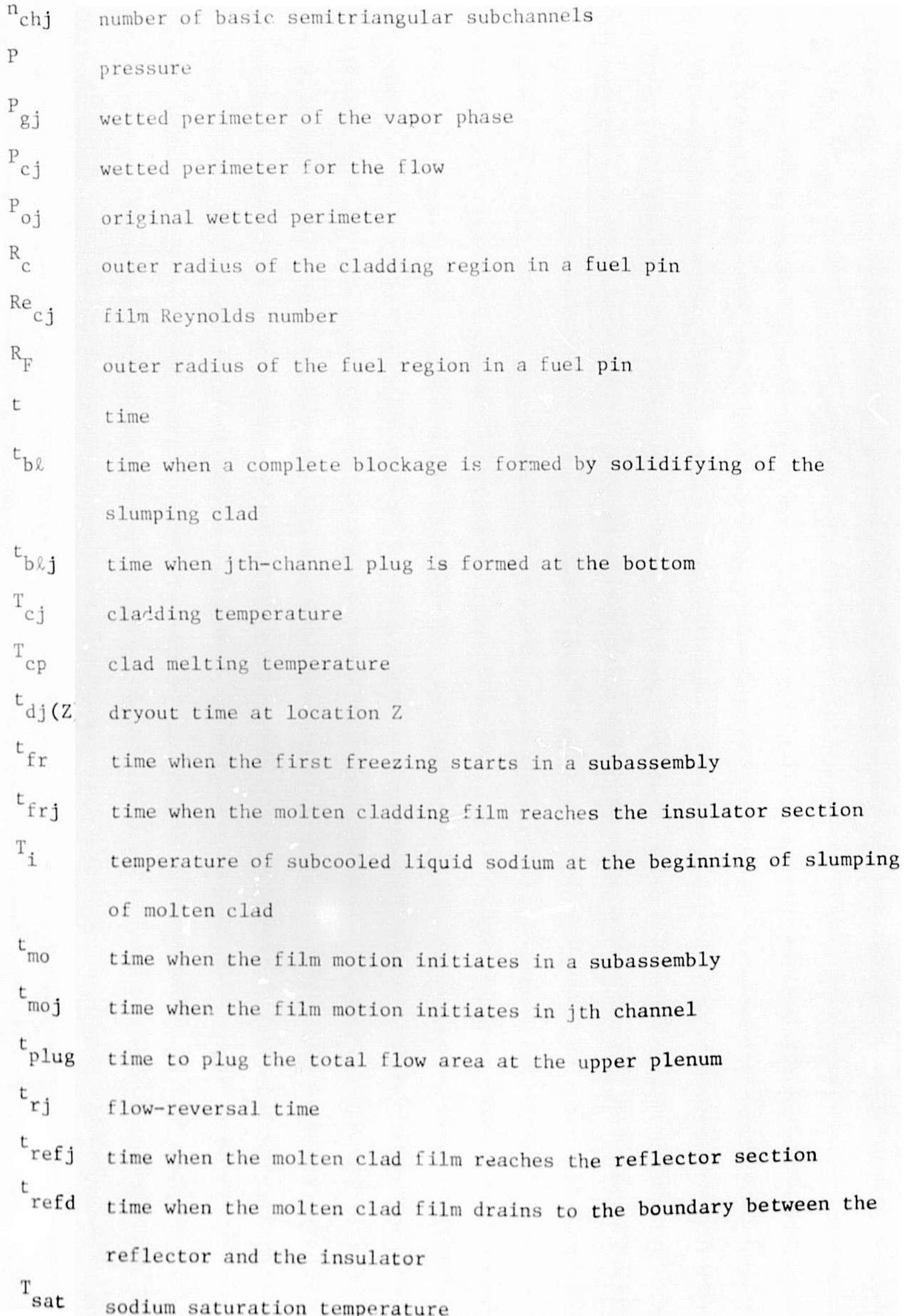


NOMENCLATURE 
$t_{\text {sl }} \quad$ time when the first slumping starts in a subassembly

$t_{s l j} \quad$ starting time of slumping of molten clad into liquid sodium at the $\alpha_{o j}$ lower end of the heated section

$\mathrm{W}_{\mathrm{gj}}$

total flow diversion for $j$ th-channel sodium vapor

$z_{\text {downm }}$

$z_{\text {down } j}$

$Z_{\operatorname{moj}}$

$\mathrm{Z}_{\text {upm }}$

Zup

$\mathrm{Z}_{1 j}$

$\mathrm{z}_{2 \mathrm{j}}$

$v_{c j}$

$\mathrm{v}_{\text {frcj }}$

$v_{\text {f1ood }}$

$\mathrm{v}_{\mathrm{gj}}$

$\mathrm{v}_{\mathrm{gij}}$

$v_{\text {gfrj }}$

$\mathrm{v}_{\mathrm{gmj}}$

axial position

lowest position among the molten clad films in a subassembly

lower end of the molten clad film

position where the film motion initiates

highest position among the molten clad films in a subassembly

upper end of the molten clad film

lower end of the melted cladding section

upper end of the melted cladding section

cladding film velocity

film velocity in blockage section

steady-state flooding velocity

vapor velocity

vapor velocity at inlet

volumetric flux of sodium vapor in the upper blockage section

volumetric flux of $j$ th-channel based on $A_{j}$ in the subassembly film ${ }_{m}$ section

Greek Symbols

$\alpha_{j} \quad$ void fraction of the vapor phase based on the flow area with stripp fuel pins

$\alpha_{\mathrm{drj}} \quad$ fraction of $\mathrm{A}_{j}$ available for clad accumulation

$\alpha_{g j} \quad$ void fraction of the vapor phase based on the real flow area (the flow area of the vapor and mo1ten cladding) ratio of flow area of intact channel to flow area with stripped fuel pins

ratio of wire to clad area

vapor source per volume

total subassembly pressure drop

prussure drop in subassembly film section

thickness of molten clad film

original cladding thickness

thickness of the solidified layer

deflooding parameter to account for the smoothing of the film after

flow reversal or during transient flooding prosess

thermal diffusivity of the cladding

length of the molten clad film in $j$ th channel

length of the melted-cladding section in $j$ th channel

level of drained molten cladding

length of the frozen clad layer above the fuel

leugth of subassembly blockage section

total length of the molten clad film section for a subassembly

length of the molten clad film

length of the bottom blockage

viscosity of molten cladding

liquid-cladding shear stress from wall

interfacial shear stress

cladding density

vapor density 
MULTICHANNEL CLAD-RELOCATION MODEL FOR

FAST-REACTOR LOSS-OF-FLOW ACCIDENTS

by

M. Ishii, W. L. Chen, and M. A. Grolmes

\section{ABSTRACT}

During an unprotected undercooling accident in a liquid-metal

fast breeder reactor, the motion and relocation of the molten cladding can be important because of its potentially significant effect on reactivity, blockage formation, and subsequent fuel motion. The present study analyzes the clad relocation problem based on a multichannel film-flow model.

The important aspects considered in the analysis are the nonuniform transverse clad-melting pattern and diversions of sodiumvapor flow within a subassembly. It has been shown that the motion of molten clad and subsequent blockage formations can be significantly influenced by this interconnected channel effect. Several sample calculations have been made in order to demonstrate these points.

\section{INTRODUCTION}

In a hypothetical unprotected loss-of-flow accident in liquid-metal fast breeder reactors, sodium coolant is rapidly heated to boiling. Because of a large density ratio between the liquid and vapor sodium, and because of the unstable characteristics of the sodium bolling, the reentry of the liquid sodium is prevented once a subassembly is voided. Consequently, the sodium boiling leads to the dryout and virtual loss of cooling from cladding surfaces. Because of the continuous internal heat generation from the fuel pins, 
melting of clad anc fuel occurs soon after the subassembly voiding. This will lead to the motion and relocation of the cladding and fuel materials. The clad motion upon melting is considered to be important in determining the reactivity effect, blockage formation, and its effect on subsequent fuel motion.

It can be said that sodium boiling and vapor streaming significantly affect the timing and extent of clad relocation. By knowing the local dryout time from a thermo-hydraulic analysis of coolant channels, ${ }^{1}$ the clad melting time can be predicted from a simple thermal transient model for fuel pins. ${ }^{2}$ The time interval between the dryout and clad melting depends on the rate of heat generation. At the normal power level, the dryout is followed by clad melting in a time of the order of $1 \mathrm{~s}$; the melting of fuel occurs within several seconds thereafter.

Based on these observations, a simple one-dimensional clad-motion model had been developed previously. ${ }^{3}$ The model is satisfactory when each subassembly can be lumped into one channel and the incoherency effects ${ }^{4}$ within a subassembly can be neglected. However, the one-dimensional model cannot take into account the effects of geometrical differences and thermal incoherency among the interconnected subchannels.

The present multichannel clad-relocation model is an extension of the one-dimensional clad-motion model ${ }^{3}$ to the case with interconnected parallel channels. During the course of an LMFBR core-disruptive accident, a nonuniform transverse clad-melting pattern develops within each subassembly due to incoherence effects. ${ }^{4}$ This is because power skewing and heat losses to the hexcan wall can generate radial temperature differences of approximately $200^{\circ} \mathrm{C}$ at boiling inception. Hence, the time of clad-surface dryout and of clad-motion initiation can be significantly different among subchannels. 
These incoherence effects of clad melting result in significant differences in hydraulic resistance among subchannels, because the length of the molten clad films and subsequent developments of a blockage formation due to freezing of clad films are not uniform within a subassembly. Since the subchannels are interconnected, this will lead to sodium-vapor diversions in order to equalize the axial pressure drops. In view of the fact that the interfacial shear forces on the molten clad films due to the streaming vapor are the main upward driving force, the motion of molten clad can be significantly influenced by interconnected-channel effects. ${ }^{5}$

It is expected that the initial upward clad motion in the central (hotter) subchannels is severely limited due to the sodium-vapor diversion to peripheral (colder) subchannels. This also should have a significant influence on the blockage formation in the central region. On the other hand, molten clad in the colder subchannels moves much like the one predicted by the one-dimensional model, since at this stage the bypass effect of sodium vapor is nonexisting. The purpose of the present study is to develop a multidimensional cladmotion model based on a rough-wavy film-flow model with upper and bottom plugging mechanisms due to freezing of the molten clad on cold surfaces. The important aspects to be included in the analysis are the subassembly incoherency effects and the interconnected-channel effects which permit the diversion of sodium vapor. 


\section{DESCRIPTION OF THE SYSTEM}

Current LMFBR core design is based on the arrangement of fuel pins in a number of hexagonally shaped subassemblies. A large number of cylindrical fuel pins are arranged in a triangular array and contained in each subassembly duct, as shown in Fig. 1. These pins are separated by means of spacer wires

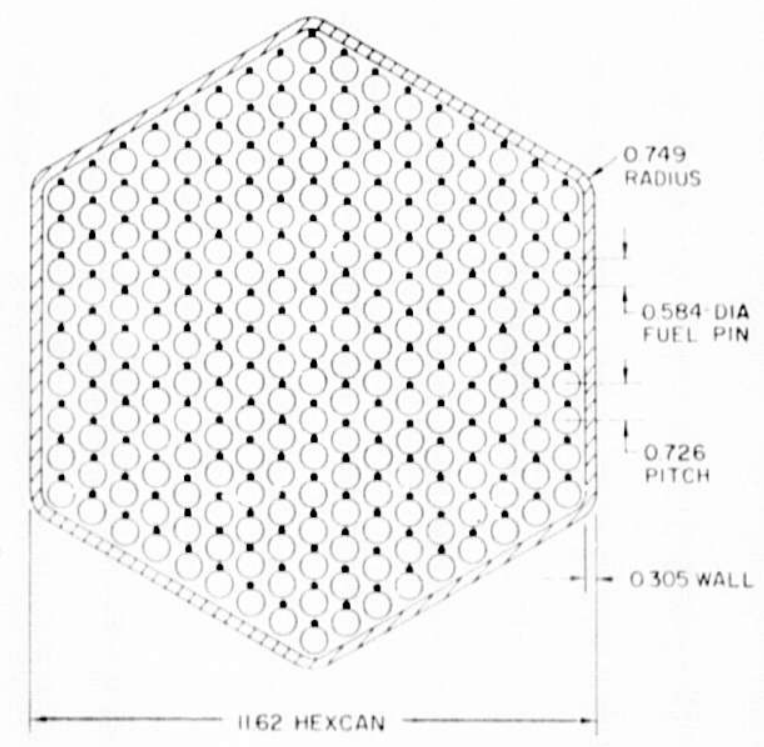

Fig. 1. Cross Section of LMFBR Subassembly Typical of FFTF and CRBR (Dimensions in centimeters). (ANL Neg. No. 900-2521, Rev. 1.) which go spirally around the pins.

Individual triangular elements form

the basic subchannel configuration as

shown in Fig. 2. In the present analysis, these subchannels are lumped

into several computational channels according to their thermohydraulic characteristics. In the absence of power skewing, subdivision into ringlike regions brings about great economy. It is estimated that the subassembly incoherency effects on the clad relocation can be satisfactorily modeled

by using three channels.

The multichannel clad-relocation model considered in the present analysis is shown in Figs. 2 and 3. It was assumed that the subassembly was voided prior to the onset of molten-clad motion. The origin of the axial coordinate was taken at the lower end of the fuel. After the volding of liquid sodium from the fuel section, the sodium vapor is generated at the bottom of the heated section by chugging of the lower liquid level. Reentry of the upper liquid sodium into the hot core will not take place, since in whole-core lossof-flow accidents the rate of evaporation generally exceeds the rate of 


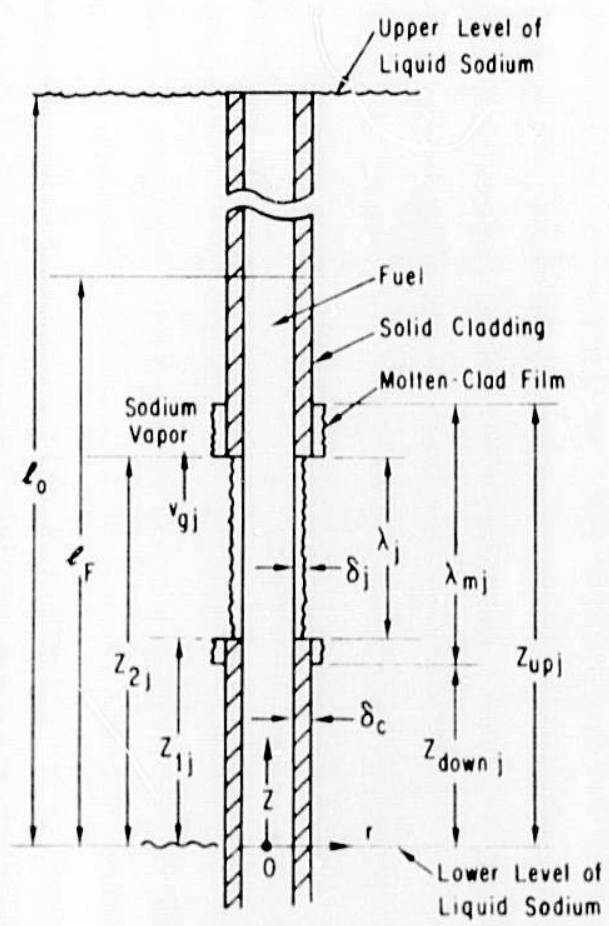

Fig. 2. Typical Subchannel in jth Channel.

(ANL Neg. No. 900-76-650.)

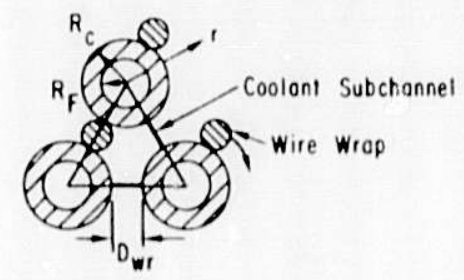

Fig. 3. Multichannel System.

(ANL Neg. No. 900-76-652.)

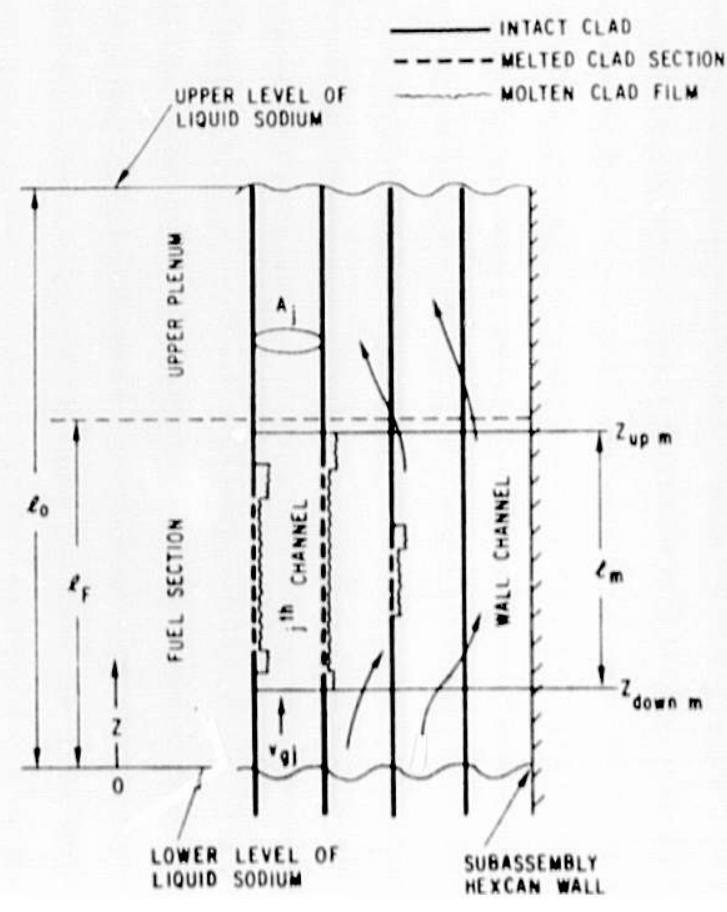


condensation in the channel as long as the power generation is not severely reduced. Reentry is considered possible only after complete blockage formation. In the present model the average lower liquid level was taken at the bottom of the heated section $(\mathrm{z}=0)$ and the upper level at the end of the fuel pin $\left(Z=\ell_{0}\right)$. The pressure drop imposed on the system $\ell_{0}$ may be approximated by the liquid-sodium hydrostatic head. ${ }^{6}$ This pressure drop roughly corresponds to a vapor velocity of $80 \mathrm{~m} / \mathrm{s}$ at the onset of clad melting, far exceeding the flooding velocity. ${ }^{7}$ On the other hand, newly developed film-entrainment criteria $^{8}$ indicate that the critical vapor velocity for the present case is about $120 \mathrm{~m} / \mathrm{s}$. In view of the above facts, it is expected that the molten clad moves as a film rather than as entrained droplets.

A typical subchannel in the $j$ th computational channel is shown in Fig. 2. The length of the heat-generating section is denoted by $l_{F}$, whereas the upper and lower ends of the melted cladding section are $z_{2 j}$ and $z_{1 j}$, respectively. The total length of the molten-clad film is denoted by $\lambda_{\mathrm{mj}}$, the thickness of the film by $\delta_{j}$, and the initial solid-cladding thickness by $\delta_{c}$. The location of the upper and lower ends of the film are $z_{\text {upj }}$ and $z_{\text {downj }}$. The radii of the fuel and cladding prior to melting are given by $R_{F}$ and $R_{C}$, and the shortest distance between pins is denoted by $\mathrm{D}_{\mathrm{wr}}$, which is approximately the diameter of the wire wrap. The total flow area of an intact $j$ th channel is denoted by $A_{j}$. For the case of the wall channel adjacent to a subassembly haxcan, the subchannel geometries are somewhat different, since one or two of the fuel pins are replaced by the duct wall as a bounding surface (see Fig. 1). This will bring considerable thermohydraulic differences between the central and wal1 subchannels.

Figure 3 shows the interconnected parallel-channel clad-motion model. The highest position of all the molten clad films is denoted by $Z_{\text {upm }}$ such that 


$$
\mathrm{Z}_{\mathrm{upm}}(\mathrm{t}) \equiv \max \left[\mathrm{Z}_{\mathrm{upj}}\right] \cdot
$$

On the other hand, the lowest film position $Z_{\text {downm }}$ is given by

$$
\mathrm{Z}_{\text {downm }}(t) \equiv \min \left[\mathrm{Z}_{\text {downj }}\right]
$$

Then the subassembly film section is given by $\mathrm{z}_{\text {downm }} \leq \mathrm{Z} \leq \mathrm{z}_{\text {upm }}$, and its length by

$$
\ell_{\mathrm{m}} \equiv \mathrm{Z}_{\text {upm }}-\mathrm{Z}_{\text {downm }} \cdot
$$

Because of the upward driving force due to high sodium-vapor velocity, it is possible that the molten steel reaches the unheated region and freezes. Whether this frozen layer of steel forms a partial blockage or a total channel plug depends on the extent of the upward penetration as well as the thermal inertia and the temperature of the upper section of the fuel pins, that is, of the blanket or inconel reflector section. The partial flow blocakge due to the frozen steel layer is treated as a flow nozzle with a changing nozzle size.

After clad-film flow reversal, the film drains down the channel and eventually slumps into the cold liquid sodium. The solidification of the molten clad and formation of the flow blockage due to bottom freezing are also included in the subsequent analysis. In order to model the interconnected parallelchannel effects, sodium-vapor flow in each channel is allowed to divert to other channels according to the hydraulic resistances of the sections of the channe1s. However, it was assumed that interchannel transfer of molten clad materials does not take place until the formation of the bottom blockage. This assumption is consistent with the film-flow model used in the analysis. In the present analysis, a subassembly is divided into several axial sections, and the equal axial-pressure-drop condition has been imposed on each of these sections. This assumption implies that the transverse diversions of 
sodium vapor flows occur according to the changes in the axial hydraulic resistances and that the transverse pressure drop and flow resistance can be considered as a secondary effect. 


\section{ANALYSIS}

\section{A. Basic Film Motion}

From the thermohydraulic analysis of sodium voiding and the thermal analysis of fuel and clad, the upper and lower melting boundaries and the length of the melted cladding section $\left(z_{2 j}, z_{1 j}\right.$, and $\left.\lambda_{j}=z_{2 j}-z_{1 j}\right)$ can be determined. $1,2,9$

The thickness of the film was assumed to be uniform, based on two considerations. First, the rapid propagations of melting fronts both upward and downward have the effect of smoothing the film thickness. Second, the model is based on the rough-wavy film-flow model. This implies that the local wave amplitude of two to three times the mean film thickness is permissible, as reflected on the roughness parameter. This roughness effect is the dominant factor in determining the interfacial shear forces and the film motion. The uncertainty of predicting the interfacial shear forces in the transient condition outweighs the assumption of uniform film thickness. Under the assumption, the conservation of molten clad before froezing can be expressed by

$$
\delta_{j}=\delta_{c} \lambda_{j} / \lambda_{m j} .
$$

The absence of the interchannel mixing of molten clad in the above equation is consistent with the assumption that the molten steel moves as a film without being entrained into sodium-vapor flows. ${ }^{8}$

The original flow area per channel is denoted by $A_{j}$, the flow area without cladding by $A_{\infty j}$, and the vapor flow area by $A_{g j}$. Then the void fraction of the vapor phase based on the flow area with stripped fuel pins (without clad) is defined as $\alpha_{j} \equiv A_{g j} / A_{\infty j}$, and the reference vold fraction without molten clad is given by $\alpha_{o j}=A_{j} / A_{\infty j}$. On the other hand, the void fraction of the vapor phase based on the real flow area, that is, the flow area of the 
vapor plus that of molten clad, is defined by $\alpha_{g j} \equiv A_{g j} /\left(A_{g j}+A_{c m j}\right)$, where $A_{c m j}$ is the molten-clad flow area per channel. The original hydraulic diameter of an intact channel is given by $D_{o j} \equiv 4 A_{j} / P_{o j}$, whereas the hydraulic diameter for the film section is given by $D_{j} \equiv 4\left(A_{g j}+A_{c m j}\right) / P_{c j}$. Simflarly, the gas hydraulic diameter is $\mathrm{D}_{\mathrm{gj}} \equiv 4 \mathrm{~A}_{\mathrm{gj}} / \mathrm{P}_{\mathrm{gj}}$. Here $\mathrm{P}_{\mathrm{oj}}, \mathrm{P}_{\mathrm{cj}}$, and $\mathrm{P}_{\mathrm{gf}}$ are the original, film-section, and vapor-phase wetted perimeter, respectively.

The basic formulation for the sodium vapor and molten-clad film motion is similar to the one-dimensional model; ${ }^{3}$ however, the present study takes account of the interconnected-channel effect which has not been considered in the previous model. Now the axial length of a subassembly is divided into intact clad sections $\left(Z \leq z_{\text {downm }}\right.$ and $\left.z \geq z_{\text {upm }}\right)$ and the subassembly film section $\left(\mathrm{Z}_{\text {downm }} \leq \mathrm{Z} \leq \mathrm{Z}_{\text {upm }}\right)$, as shown in Fig. 3 .

The one-dimensional vapor-continuity equation can be given by

$$
\frac{\partial}{\partial t}\left(A_{g j} \rho_{g}\right)+\frac{\partial}{\partial Z}\left(A_{g j} \rho_{g} v_{g j}\right)=\left(A_{g j}+A_{c m j}\right) \Gamma_{g j}-W_{g j} .
$$

During the clad-motion phase of loss-of-flow accidents in the present analysis, the vapor phase is taken as incompressible, and no source of gas either due to fission-gas release or steel vaporization is considered. The present model assumes that the vapor volumetric flows within each channel and axial section are uniform, and that the interchannel mixing occurs at the boundaries of these axial sections. This assumption is consistent with the integral momentumbalance equations to be used for vapor and molten-clad motions in the subsequent analysis. Furthermore, the magnitude of the vapor velocity before deflooding (20 to $80 \mathrm{~m} / \mathrm{s})$ far exceeds the axial propagation velocity of melting boundaries, which are of the order of $1 \mathrm{~m} / \mathrm{s}$ under the normal power level. Consequent1y, the overa11 mass balance can be reduced to

$$
\sum_{j=1}^{n} A_{j} v_{g i j}=\sum_{j=1}^{n} A_{j} v_{g m j},
$$


where $v_{g i j}$ is the $j$ th-channel vapor velocity over the intact clad sections and $v_{g m j}$ is the $j$ th-channel volumetric flux of vapor based on $A_{j}$ in the subassembly film section: $z_{\text {downm }} \leq z \leq z_{\text {upm }}$. On the other hand, the vapor-continuity equation in the subassembly film section reduces to

$$
v_{g j}(z, t)=\frac{\alpha_{o j}}{\alpha_{j}} v_{g m j}(t) .
$$

The jth-channel equation of motion for the sodium vapor is given by

$$
\frac{\partial}{\partial t}\left(A_{g j} v_{g j}\right)+\frac{\partial}{\partial Z}\left(A_{g j} v_{g j}^{2}\right)=-\frac{A_{g j}}{\rho_{g}} \frac{\partial p}{\partial Z}-A_{g j} g-\frac{\tau g j}{P_{g j}}-M_{g j},
$$

where $M_{g j}$ is the loss of momentum due to interchannel mixing or flow diversions. By introducing an interfacial friction factor, the shear stress can be given as

$$
\tau_{g j}=\left(\frac{f_{s j}}{4}\right)\left[1+300 \varepsilon_{j} \delta_{j} / D_{j}\right] \frac{\rho_{g} v_{g j}\left|v_{g j}\right|}{2} .
$$

Here $f_{s j}$ is the smooth-pipe friction factor for the vapor phase and $\varepsilon_{j}$ the deflooding parameter to account for the transient flooding condition.

By use of the continuity equation (4) and the approximate forms for the effects of void-fraction changes on the velocity and hydraulic diameter, ${ }^{3}$ the pressure drop in the subassembly film section reduces to

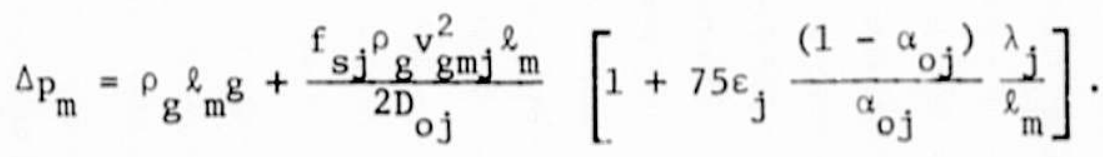

On the other hand, for the intact clad sections, we have

$$
\Delta \mathrm{p}-\Delta \mathrm{p}_{\mathrm{m}}=\rho_{\mathrm{g}}\left(l_{\mathrm{o}}-l_{\mathrm{m}}\right) \mathrm{g}+\frac{\mathrm{f}_{\mathrm{sj}}}{2 \mathrm{D}_{\mathrm{oj}}} \rho_{\mathrm{g}} \mathrm{v}_{\mathrm{gij}}^{2}\left(l_{\mathrm{o}}-l_{\mathrm{m}}\right) .
$$

In deriving the above equations, we have assumed that the inertia terms are small (under standard conditions without pressurization of the core the inertia terms are of the order of $1 \%$ of the hydrostatic head of the liquid sodium). 
Equations (7) and (8) are integrated forms of the vapor-momentum equation. In the present formulation, the overall pressure drop $\Delta p$ is considered as the input information. Without considerable reduction in power, the sodium chugging and the lack of a heat sink prevents reentry of the liquid sodium into the subassembly. In this case, the total channel pressure drop over the voided section fluctuates due to the sodium chugging. By averaging out the effect of chugging on the pressure and recalling that in this stage of lossof-flow accidents most of the 1 iquid-sodium flow has been 1 ost, $\Delta p$ may well be approximated by the liquid-sodium hydrostatic head. ${ }^{6}$

The $\mathrm{jth}$-channel equation of motion for the molten clad is given by

$$
\frac{\partial\left(A_{c m j} v_{c j}\right)}{\partial t}+\frac{\partial}{\partial Z}\left(A_{c m j} v_{c j}^{2}\right)=-\frac{A_{c m j}}{\rho_{c}} \frac{\partial p}{\partial Z}-A_{c m j} g+\frac{P_{g j^{\tau}}{ }_{g j}-P_{c j}{ }^{\tau} c j}{\rho_{c}},
$$

where the wall shear stress $\tau_{i j}$ can be given by

$$
\tau_{c j}=\left(\frac{f_{c j}}{4}\right) \frac{\rho_{c} v_{c j}\left|v_{c j}\right|}{2} .
$$

Since the film Reynolds number for the molten clad, defined by $\operatorname{Re}_{\mathrm{cj}} \equiv 4 \rho_{\mathrm{c}} \mathrm{v}_{\mathrm{cj}} \delta_{j} / \mu_{\mathrm{c}}$, is of the order of $2000\left(\right.$ at $\mathrm{v}_{\mathrm{cj}}=120 \mathrm{~cm} / \mathrm{s}$ and $\delta=0.0381$ $\mathrm{cm}$ ) or less, the use of the laminar wall friction factor ${ }^{10}$ suffices for most cases. Thus we have $\mathrm{f}_{\mathrm{cj}}=64 / \mathrm{Re} \mathrm{cj}_{\mathrm{j}}$, which is valid for high-shear flows. However, if the gravity effect on the shear-stress distribution in the film is important, some modification may be appropriate. Based on the steady-state velocity profile for a thin laminar film flow, the modified friction factor ${ }^{11}$ becomes

$$
f_{c j}=-\frac{8}{\rho_{c} v_{c j}\left|v_{c j}\right|}\left\{-\frac{2 v_{c j}{ }_{c}}{\delta_{j}}+\frac{1}{3}\left(\rho_{c}-\rho_{g}\right) \delta_{j} g\right\} .
$$

For a slow transient process the wall friction factor given by Eq. (11) is evidently more accurate, particularly for countercurrent flow situations. 
However, for a rapidly accelerating upward film flow there are some uncertainties in applying Eq. (11), because there may not be sufficient time to develop a downwardly convex parabolic velocity profile. In such a case the wall friction factor is expected to be somewhere between the above two expressions.

Integrating the liquid-momentum equation over the jth-channel filmsection length $\lambda_{\mathrm{mj}}$ by the method used in Ref. [3], we obtain

$$
\begin{aligned}
& \frac{1}{\lambda_{j}} \rho_{c} \frac{d\left(v_{c j} \lambda_{j}\right)}{d t}=-\frac{2}{3}\left(\rho_{c}-\rho_{g}\right) g-\frac{2 \mu_{c} v_{c j}}{\delta_{c}{ }^{2}}\left(\frac{\delta_{c}}{\delta_{j}}\right)^{2} \\
& +\frac{f_{s j}}{2 D_{o j}} \frac{\rho_{g} v_{g m j}^{2}}{\left(1-\alpha_{o}\right)}\left[1+75 \varepsilon_{j}\left(1-\alpha_{o j}\right)+\alpha_{o j}\left(\lambda_{m j} / \lambda_{j}-1\right)\right] .
\end{aligned}
$$

In view of Eq. (7), the vapor volumetric flux $v_{g m j}$ can be replaced by the film-section pressure drop $\Delta \mathrm{p}_{\mathrm{m}}$ as

$$
\begin{aligned}
& \frac{1}{\lambda_{j}} \rho_{c} \frac{d\left(v_{c j} \lambda_{j}\right)}{d t}=-\frac{2}{3}\left(\rho_{c}-\rho_{g}\right) g-\frac{2 \mu_{c} v_{c j}}{\delta_{c}^{2}}\left(\frac{\delta_{c}}{\delta_{j}}\right)^{2} \\
& +\frac{\Delta_{m}-\rho_{g} g_{m}}{\left(1-\alpha_{o j}\right) l_{m}} \frac{\left[1+75 \varepsilon_{j}\left(1-\alpha_{o j}\right)+\alpha_{o j}\left(\lambda_{m j} / \lambda_{j}-1\right)\right]}{\left[1+75 \varepsilon_{j}\left(1-\alpha_{o j}\right) \lambda_{j} /\left(\alpha_{o j}{ }_{m}\right)\right]} .
\end{aligned}
$$

In order to solve the above film-motion equation, it is necessary to specify the relation between the molten-clad length and the film velocity. By denoting the time when the clad motion starts in $j$ th channel as $t_{m o j}$ and in the subassembly as $t_{\mathrm{mo}}$, that is $t_{\mathrm{mo}}=\min \left(t_{\mathrm{moj}}\right)$, we have

$$
z_{2 j}\left(t_{m o j}\right)=z_{1 j}\left(t_{m o j}\right) \equiv z_{m o j} .
$$

Here $Z_{\text {moj }}$ is the point where the film motion initiates. In general, we have

$$
\lambda_{m j}=\lambda_{j}(t)+\Delta \lambda_{\text {upj }}(t)+\Delta \lambda_{\text {downj }}(t) .
$$

For up flow in which $v_{c j}>0$, we have: 
If

$$
\int_{t_{m o j}}^{t} v_{c j}(t) d t \geq z_{2 j}(t)-z_{m o j}
$$

then

$$
\Delta \lambda_{u p j}(t)=\int_{t_{m o j}}^{t} v_{c j}(t) d t-\left[z_{2 j}(t)-z_{m o j}\right] ;
$$

otherwise

$$
\Delta \lambda_{\operatorname{upj}}(t)=0 .
$$

In the down flow in which $v_{c j}<0$, the overlapped length in the lower section of the film is given by:

If

$$
\int_{t_{r j}}^{t} v_{c j}(t) d t \leq z_{1 j}(t)-z_{1 j}\left(t_{r j}\right),
$$

then

$$
\Delta \lambda_{\text {downj }}=-\int_{t_{r j}}^{t} v_{c j}(t) d t+\left[z_{1}(t)-z_{1}\left(t_{r j}\right)\right] ;
$$

otherwise

$$
\Delta \lambda_{\text {downj }}=0 .
$$

Here $t_{r j}$ denotes the flow-reversal time from the upward to downward direction in terms of $v_{c j}$. These two expressions for $\Delta \lambda_{\text {upj }}$ and $\Delta \lambda_{\text {downj }}$ are based on the relation between the integral motion of the center of mass of the molten cladding material and the motion of the melting boundary.

In the case of the downward film motion, there are essentially four different sections to be considered, as shown in Fig. 4. We have

1) the main draining film with the upper boundary moving down with the center of mass of the film;

2) film mainly consisting of newly melted clad; 
3) thin film of clad left on the unmelted cladding surface at the upper section;

4) thin film or clad left on the stripped fuel surface at the upper section.

By taking into account that the amount of molten clad in sections (3) and (4) decreased rapidly because of the thinning effect due to draining and of

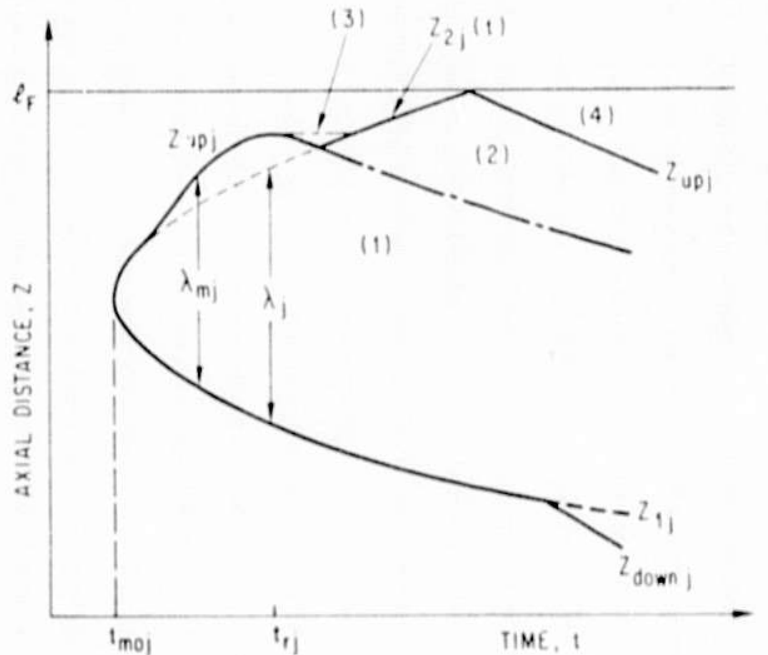

Fig. 4. Positions of Melt Front and Liquid Film. (ANL Neg. No. 900-76-652.)

the lack of supply of new molten clad, an important part of the molten clad drains as section (1) and section (2). Consequently, we shall formulate the film motion based on these sections. Therefore, we have for $t_{r j} \leq t$ and $z_{u p j}>z_{2 j}$

$$
z_{u p j}=z_{u p j}\left(t_{r j}\right)+\int_{t_{r j}}^{t} v_{c j}(t) d t
$$

and $\Delta \lambda_{\text {upj }}=z_{\text {upj }}-z_{2 j}$. However, when $z_{2 j} \geq z_{\text {upj }}$, the position of the top of the film is temporary redefined as $z_{u p j}=z_{2 j}$ until $z_{2 j}$ reaches the top of the fuel. The parameter $\Delta \lambda_{\text {upj }}$ becomes negative when the film drains down after $Z_{2 j}$ reaching $\ell_{F}$.

It is noted here that the integral momentum equations for the vapor and the 1 iquid phase derived above do not apply exactly to the case with $\Delta \lambda_{\text {upj }}<0$ due to the existence of the uncovered fuel section. However, in view of the compensating effects of widening hydraulic diameter at the bare fuel section and the increased frictional resistance at the lower overlapped section, the integral gas-momentum balance, Eq. (7), is approximately valid for this case also. Similarly, in the integral liquid-momentum balance, Eq. (13), the mass 
transfer and the interfacial friction terms for the case with $\Delta \lambda_{\text {upj }}<0$ are only approximately correct. Furthermore, if there is a considerable blockage formation in the upper insulator or reflector section, the vapor velocity will be reduced such that the effect of the interfacial friction term on the film motion becomes insignificant. These assumptions are justified also on the basis of the overall simplicity and continuity of the model.

\section{B. Upper Freezing}

When the molten clad film reaches the unheated section by the upward motion induced by the sodium-vapor drag, liquid starts to freeze upon contact with the cold cladding surfaces. These solidified layers of cladding material over the original channel surface act as flow blockages for both the moltenclad flow and the streaming sodium-vapor flow.

The nature of the blockage formation is largely governed by the initial temperature of the upper plenum structure and its thermal capacity. In the case of the Fast F1ux Test Facility (FFTF) there are two different sections of practical importance just above the fuel section. As shown in Fig. 5, the insulator section stands next to the heated section, and the pellets section has a very low conductivity similar to that of fuel. Above the insulator section in FFTF there is a reflector which is made of

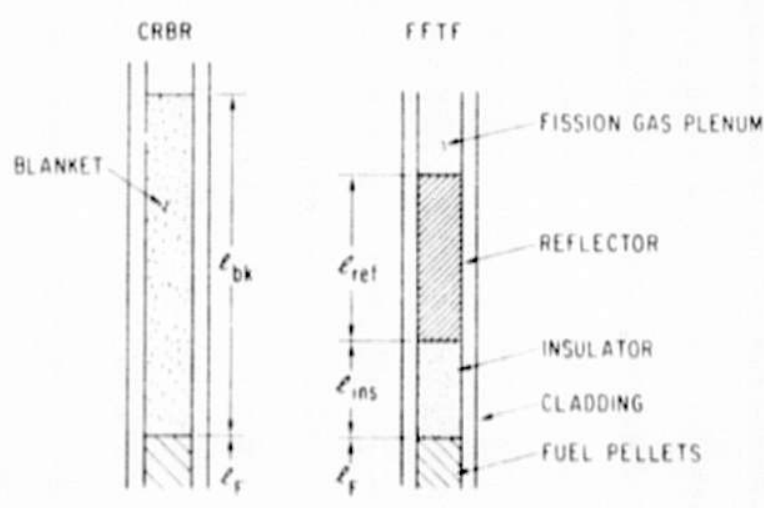

(0) UPPER PLENUM GEOMETRY
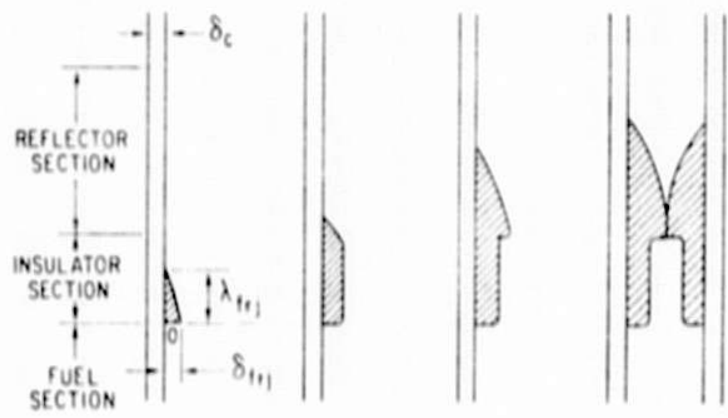

(D) VARIOUS SOLIOIFIED LATER CONFIGURATIONS (FFTF)

Fig. 5. Freesing in Upper Plenum. (ANL Neg. No. 900-76-648.) 
solid inconel of about $15-\mathrm{cm}$ axial length. However, in Clinch River Breeder Reactor (CRBR) or current conceptual designs of commercial power plants there will be an axial blanket region directly above the fuel region, which consists of depleted $\mathrm{UO}_{2}$ extending approximately $36 \mathrm{~cm}$ in axial length (CRBR). The heat generation in the blanket region is considerably lower than in the fuel region and diminishes rapidly to zero with increasing distance from the fuel. In analyzing the freezing process at the upper plenum, it is necessary to make a distinction in these structural differences because of the significant difference in the thermal conductivities of the materials.

In the short time scale of our concern, the insulator or blanket pellets can be considered as a completely insulating material such that the solid cladding and its thermal inertia govern the solidification of the molten clad in this section. On the other hind, in the reflector section the whole cross section is essentially metal; thus the thermal inertial of the inconel reflector should be included in the analyses. The basic freezing model for these different sections has been developed in connection with the one-dimensional clad-motion model. ${ }^{3}$

Let us denote the time when the molten clad reaches the insulator section by $t_{f r j}$; then $z_{u p j}\left(t_{f r j}\right)=l_{F}$. The temperature of the molten clad which reaches the upper plenum may be approximated by the clad melting temperature $\mathrm{T}_{\mathrm{cp}}$, since it has flowed over the solid cladding surface having $\mathrm{T}_{\mathrm{cj}} \simeq \mathrm{T}_{\mathrm{cp}}$. Furthermore, the energy associated with the solidification is large such that a small difference in the initial liquid superheat above the solidification temperature is insignificant.

The temperature of the upper-plenum cladding before contacting the molten metal is estimated to be the same as the sodium saturation temperature $\mathrm{T}_{\text {sat }}$, because of the pre-existing sodium bolling and the vapor streaming. By taking 
$\mathrm{T}_{c j}=\mathrm{T}_{\text {sat }}$ in the unheated section axial conduction from the fuel section through the cladding is neglected.

By knowing the initial temperature of the molten clad and the upperplenum clad temperature, the thickness of the frozen layer in the insulator section can be given by

$$
\delta_{f r j}=2 A \sqrt{k_{c}\left(t-t_{f r j}\right)} \text {, }
$$

where $k_{c}$ is the thermal diffusivity of the cladding and parameter $A$ is a complicated implicit function of $\mathrm{C}_{\mathrm{c}}\left(\mathrm{T}_{\mathrm{cp}}-\mathrm{T}_{\text {sat }}\right) / \mathrm{L}_{\mathrm{c}} \cdot$ However, for $\mathrm{C}_{\mathrm{c}}\left(\mathrm{T}_{\mathrm{cp}}-\mathrm{T}_{\mathrm{sat}}\right) / \mathrm{L}_{\mathrm{c}}>1.0$, which is applicable to our case, it can be approximated by

$$
A \doteq \frac{\ln \left[C_{c}\left(T_{c p}-T_{s a t}\right) / L_{c}\right]+1.09}{3.28} .
$$

On the other hand, the heat flux at the solidifying interface is given by $k_{c} A_{c} / C_{c} \sqrt{k_{c}\left(t-t_{f r j}\right)}$. Therefore, in the insulator section solidification will be terminated within a time

$$
\Delta t_{f r j}=\frac{1}{k_{c}}\left\{\frac{\delta_{c}}{2 A} \frac{C_{c}\left(T_{c p}-T_{s a t}\right)}{L_{c}}\right\}^{2} .
$$

For example, with the typical. FFTF condition of $\mathrm{T}_{\mathrm{cp}}=1427^{\circ} \mathrm{C}, \mathrm{T}_{\text {sat }}=899^{\circ} \mathrm{C}$, and $\delta_{c}=0.0381 \mathrm{~cm}$, we have $\Delta \mathrm{t}_{\mathrm{frj}}=0.061 \mathrm{~s}$. After $\Delta \mathrm{t}_{\mathrm{frj}}$ from the initial contact time the heat sink of the cladding will be completely removed by the latent heat transport. Therefore, we have for the insulator section the maximum thickness of the solidified layer given by

$$
\delta_{f r j}=\left\{\begin{array}{lll}
0 & \text { for } & t-t_{f r j}<0 \\
2 A \sqrt{k_{c}\left(t-t_{f r j}\right)} & \text { for } & 0 \leq t-t_{f r j} \leq \Delta t_{f r j} \\
2 A \sqrt{k_{c} \Delta t_{f r j}} & \text { for } & t-t_{f r j}>\Delta t_{f r j} .
\end{array}\right.
$$


In the subsequent analysis, the ini-

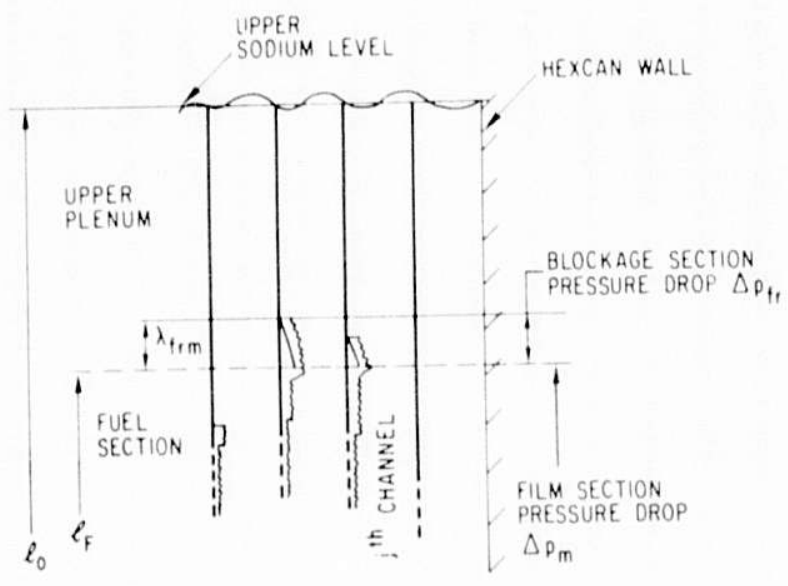

where $\lambda_{f r j}$ is the length of the frozen clad layer in the $j$ th channel. On the

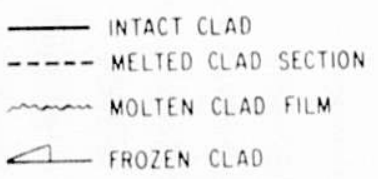

other hand, by denoting the volumetric

flux of the sodium vapor by $v_{g f r j}$ in

Fig. 6. Upper Freezing.

the blockage section, the vapor-

(ANL Neg. No. 900-76-653.)

continuity equation reduces to

$$
\sum A_{j} v_{g_{i} r j}=\sum A_{j} v_{g i j} .
$$

The pressure drop at the blockage section may be approximated by the twophase-flow nozzle resistance as in the case of the one-dimensional model; thus we have

$$
\Delta p_{f r}=K_{f r j} \frac{\rho g v_{g f r j}^{2}}{2}
$$

with

$$
K_{f r j}=\frac{C_{f r j} \delta_{f r j} D_{o j}}{\left(D_{o j}-C_{f r j} \delta_{f r j}\right)^{2}}\left[1-\left(\frac{1-\alpha_{o j}}{\alpha_{o j}}\right) \frac{\lambda_{j}}{\lambda_{m j}^{*}}\right]^{-5}+\frac{f_{s j}}{2 D_{o j}} \lambda_{f r m},
$$

where $\lambda_{\mathrm{mj}}^{*}$ is the film length at the beginning of freezing and the structural parameter $\mathrm{C}_{\mathrm{frj}}$ is given by

$$
C_{f r j}=4\left[\frac{2 \pi R_{c} n_{p i n j}}{n_{c h j} P_{o j}}\right] \text {. }
$$


Here $\mathrm{n}_{\text {pinj }}$ and $\mathrm{n}_{\mathrm{chj}}$ denote the equivalent numbers of fuel pins and of basic semitriangular subchannels in the $j$ th computational channel. Therefore the physical meaning of the term in the bracket of Eq. (26) is the ratio of the fuel-pin wetted perimeter to the total wetted perimeter. When ring-type channels are used, the value of $\mathrm{C}_{\text {frf }}$ is about 3.22 except for the wall ring, where it is approximately 1.91. Because of the added pressure drop at the blockage, the smooth-section momentum balance, Eq. (8), should be modified as

$$
\Delta p-\Delta p_{m}-\Delta p_{f r}=\rho_{g}\left(l_{o}-l_{m}-\lambda_{f r m}\right) g+\frac{f}{2 D_{o j}} \rho_{g} v_{g i j}^{2}\left(l_{o}-l_{m}-\lambda_{f r m}\right) .
$$

Here the length of the active film section of the subassembly is given by $l_{\mathrm{m}}=l_{\mathrm{F}}-\mathrm{Z}_{\text {downm }}$ after $t_{\mathrm{fr}}$ and before the top of the last film drains below the top of fuel. In other words, the length of the film section is divided into two parts $\left(l_{\mathrm{m}}\right.$ and $\lambda_{\mathrm{frm}}$ ) during the freezing process.

In order to study the extent of the upper penetration and the blockage formation by the molten-clad film, it is necessary to know accurately the behavior of the molten clad at and near the top of the film. A formation of frozen layers and increases in hydraulic resistances immediately induce the diversion of the sodium-vapor flow due to the interconnected-channel effect. Therefore, the vapor shear force acting on the film above the fuel section will be considerably less than that on the main film in the heated section. Consequent1y, in contrast to the one-dimensional model, it is necessary to introduce a momentum equation for the molten-clad film in the upper-plenum section in the multichannel model.

In view of the large uncertainty in describing the motion of the leading edge of the film in the freezing section due to geometrical changes and transient nature of the two-phase flow, it was assumed that the velocity of the top of the $f 11 \mathrm{~m}, v_{f r c j}$, can be described through Eq. (12) by simply replacing 
the vapor velocity $v_{g m j}$ by that of the freezing section $v_{g f r j}$. Thus we have for $v_{f r c j} \geq 0$,

$$
\begin{aligned}
& \frac{1}{\lambda_{j}} \rho_{c} \frac{d\left(\lambda_{j} v_{f r c j}\right)}{d t}=-\frac{2}{3}\left(\rho_{c}-\rho_{g}\right) g-\frac{2 \mu_{c} v_{f r c j}}{\delta_{c}{ }^{2}}\left(\frac{\delta_{c}}{\delta_{j}}\right)^{2} \\
& +\frac{f_{s j}}{2 D_{o j}} \frac{\rho_{c} v_{g f r j}^{2}}{\left(1-\alpha_{o j}\right)}\left\{1+75 \varepsilon_{j}\left(1-\alpha_{o j}\right)+\alpha_{o j}\left(\frac{\lambda_{m j}}{\lambda_{j}}-1\right)\right\},
\end{aligned}
$$

and the initial velocity satisfies $v_{f r c j}\left(t_{f r j}\right)=v_{c j}\left(t_{f r j}\right)$. When the leading edge velocity calculated by Eq. (28) becomes negative with a positive bulkfilm velocity, $v_{f r c j}$ is taken as zero. Thus at that point the upward advancement of the film will terminate. However, the draining of film starts only when the mean film velocity $v_{c j}$ becomes negative.

By knowing the motion of the leading edge of the film, the total length of the solidified layer is given by

$$
\lambda f r j=\int_{t_{f r j}}^{t} v_{f r c j} d t \quad \text { for } t<t_{r j} \text {, }
$$

which is also the axial penetration length by the molten clad into the upperplenum region. For CRBR or commercial-reactor-type fuel pins, the thickness of the solidified layer is limited by Eq. (22), whereas for FFTF-type fuel pins, a complete blockage formation is possible due to the existence of the reflector of solid inconel. In the latter case, the time when the molten clad film reaches the reflector section is denoted by $t_{r e f j}$ and given by

$$
\lambda_{f r j}\left(t_{\text {refj }}\right)=l_{\text {ins }} \cdot
$$

The thickness of the solidifled layer in the reflector section will not exceed that given by Eq. (22) for $t \leq t_{\text {refj }}+\Delta t_{f r}$. However, $\delta_{f r j}$ starts to increase beyond $2 A \sqrt{k_{c} \Delta t_{f r}}$ after $\Delta t_{f r}$ from the time film reaches the reflector. 
The maximum possible thickness of the solidified layer corresponding to the complete blockage is given approximately by $\mathrm{D}_{\mathrm{o}} / \mathrm{C}_{\mathrm{frj}}$. On the other hand, the maximum growth of the solid layer in the reflector section is given by $2 A \sqrt{k_{c}\left(t-t_{r e f j}\right)}$, and the time necessary to plug the channel flow area after $t_{\text {refj }}$ is given by

$$
\Delta t_{\text {plugj }} \equiv t_{\text {plugj }}-t_{\text {ref j }}=\frac{1}{k_{c}}\left(\frac{D_{o}}{2 C_{f r j} A}\right)^{2} .
$$

Then the maximum thickness of the frozen layer in the upper plenum beyond $t=t_{\text {refj }}+\Delta t_{f r j}$ is given by

$$
\delta_{f r j}= \begin{cases}2 A \sqrt{k_{c}\left(t-t_{r e f j}-\Delta t_{f r j}\right)} & \text { for } t_{r e f j}+\Delta t_{f r j} \leq t \leq t_{p l u g j} \\ 2 A \sqrt{k_{c} \Delta t} t_{p l u g j} & \text { for } t_{p l u g j}<t .\end{cases}
$$

Under the standard FFTF conditions of $\mathrm{T}_{\mathrm{cP}}=1427^{\circ} \mathrm{C}, \mathrm{T}_{\text {sat }}=899^{\circ} \mathrm{C}$, and $\mathrm{D}_{\mathrm{O}}=$ $0.314 \mathrm{~cm}, \Delta t_{\text {plugj }}$ for center channels is $0.21 \mathrm{~s}$.

In a transient calculation, it is possible that the complete plug may not form due to early clad-flow reversal. The freezing process can be terminated by several possible events. In the case of the FFTF-type fuel pin the criteria for the termination of freezing in the reflector section involve i) the flow reversal, ii) the complete plug formation, and iii) dropping of the top of the molten-clad film below the reflector section. The freezing process is now divided into two categories.

In the first stage the maximum thickness of the solidified clad layer is basically expressed by Eq. (22). The solution can be applied until clad-flow reversal time $t_{r j}$ or $t_{r e f j}+\Delta t_{f r j}$, whichever happens first. In the former case the value of $\delta_{f r j}$ will be fixed at $t=t_{r j}$, whereas in the latter case 
the value of $\delta_{f r j}$ will be switched to the one given by Eq. (32). In the former case we do not consider the additional freezing effect between the time of flow reversal and the time when the molten-clad film drains out of the upper plenum.

The freezing process enters into the second stage when the thickness of the solidified layer exceeds the upper limiting value of the insulator section. In this stage the growth of the solidified layer is due to the heat sink in the reflector rather than that in the cladding. The form of the solution is essentially given by Eq. (32) with an additional freezing-termination criterion due to dropping of the molten-clad film below the reflector section. When the flow reversal occurs before the complete plug formation, i.e., $t_{p l u g j}>t_{r j}$, then the maximum penetration of solidified layer into the upper plenum is

$$
\lambda_{f r j(\max )}=\int_{t_{f r j}}^{t} v_{f r c j} d t .
$$

The molten-clad film drains to the boundary between the reflector and the insulator at $t=t_{\text {refdj }}$, which is given by

$$
\int_{t_{r j}}^{t} v_{f r c j} d t=\lambda_{f r j(\max )}-\ell_{i n s} .
$$

The growth of the solidified clad layer given by Eq. (32) will be terminated at $t=t_{\text {refdj }}$ if $t_{\text {refdj }} \leq t_{\text {refj }}+\Delta t_{\text {plugj }}$ and at $t=t_{\text {refj }}+\Delta t_{\text {plugj }}$ if $\mathrm{t}_{\text {refdj }}>\mathrm{t}_{\text {refj }}+\Delta \mathrm{t}_{\mathrm{plugj}} \cdot$

For reactors having an axial blanket region of depleted $\mathrm{UO}_{2}$ instead of the inconel reflector in the upper plenum, several factors, such as the heat generation and the initial temperature of cladding upon contact with the molten film, should be considered. By knowing the sodium-dryout time at the 
top of the fuel pin, $t_{\mathrm{dj}}\left(l_{\mathrm{F}}\right)$, and the average heat-generation rate in the blanket region, $\dot{\mathrm{q}}_{\mathrm{upj}}$, the blanket cladding temperature $\mathrm{T}_{\mathrm{cupj}}\left(\mathrm{t}_{\mathrm{frj}}\right)$ at the beginning of the freezing process can be predicted by the method given in Ref. [2]. Then the corresponding values of the parameter $A$ and $\Delta t_{f r j}$ can be calculated from Eqs. (20) and (21) by using $\mathrm{T}_{\text {cupj }}\left(\mathrm{t}_{\mathrm{frj}}\right)$ instead of the sodium saturation temperature $\mathrm{T}_{\text {sat }}$ in the equations. By substituting the new value of A into Eq. (22), the growth of a frozen layer can be determined. In view of the very small time scale involved in the initial freezing process (of the order of $0.1 \mathrm{~s}$ ) and the low value of $\dot{\mathrm{q}}_{\mathrm{upj}}$ (of the order of $10 \%$ or less of the power in the fuel region), the effect of the heat generation during $\Delta t_{f r j}$ may be neglected.

In the postfreezing stage, either a complete blockage or a partial blockage formed by the solidified layer is left in the upper-plenum region, and the molten-clad film drains down the channel. For complete blockage formation, the blockage resistance $K_{f r j}$ becomes infinite, thus $v_{g f r j}=0$. In the case of partial blockage we assume that some molten-clad film will be left on the blockage surface and that the two-phase resistance formula (25) can be extended to the postfreezing stage. This assumption leads to a smaller gas velocity and a smaller upward interfacial force for the draining molten clad.

\section{Transient Flooding and Deflooding}

Due to the increase in the interfacial resistance, sodium-vapor diversion, and possible formation of a flow blockage by freezing of molten clad, the initial high gas velocity is reduced significantly in the course of a loss-offlow accident. Therefore, it is expected that the transient deflooding or flow-reversal condition for the molten-clad film will be reached at a certain time. 
Since the transient process occurring in the system is quite rapid, the flooding and flow-reversal conditions can be significantly different from those predicted from a quasi-steady-state condition. In other words the liquid inertia may have a considerable influence on the critical gas velocity at the flow reversal and deflooding process. In analyzing the transient deflooding, two distinct cases should be considered in relation to the moltenclad motion, that is, the initiation of motion at $t_{\text {moj }}$ and the flow reversal. At $t=t_{\text {mo }}$ the clad motion for a subassembly will start, and the initial condition for the pressure gradient for the film section, $\Delta \mathrm{p}_{\mathrm{m}} / \mathrm{l}_{\mathrm{m}}$, can be obtained from the momentum and continuity equations by taking a 1 imit $t \rightarrow t_{\text {mo }}$. Thus we have $t=t_{\text {mo }}$

$$
\frac{\Delta p_{m}}{\ell_{m}}-\rho g g=\left\{\frac{\sum A_{j} v_{g i j}}{\sum A_{j} v_{g i j}\left[\left(\frac{\Delta p-\rho_{g} g_{0}}{\ell_{0}}\right)\left(1+75 \varepsilon_{j} \frac{\left(1-\alpha_{o j}\right)}{\alpha_{o j}}\right)\right]^{-4 / 7}}\right\}^{75},
$$

where $\varepsilon_{j}$ is nonzero only for channels with mobile films.

The value of the deflooding parameter $\varepsilon_{j}$ will be determined as follows. First, the film velocity and the film-section vapor velocity $v_{\text {gmj }}$ are calculated by using $\varepsilon_{j}=1$

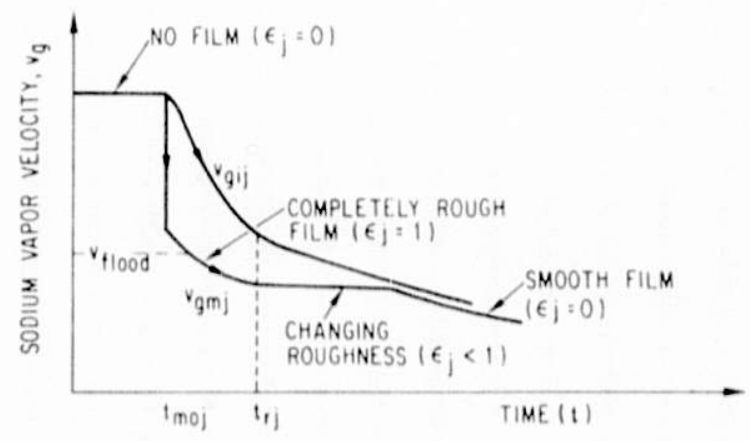
at $t=t_{m j}$. If the calculated vapor velocity $v_{g m j}$ is higher than the flooding velocity $v_{f l o o d}$, it is assumed that the film is flooded and the initial motion is upward (see

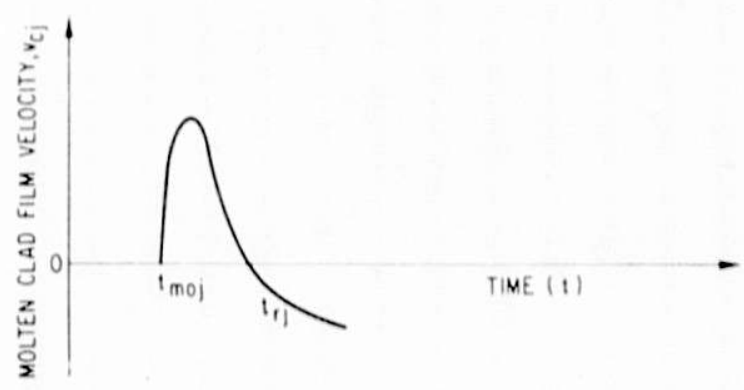
Fig. 7). Here $v_{\text {flood }}$ is calculated Eig. 7. Deflooding Process. (ANL Neg. No. 900-76-654.) 
from a standard steady-state flooding correlation. ${ }^{7}$ Under the condition applicable to the present case, $v_{\text {flood }}$ is approximately $20 \mathrm{~m} / \mathrm{s}$. In the following transient calculation $\varepsilon_{j}=1$ is retained until flow reversal. In other words, the film is in the completely rough and wavy flow regime.

On the other hand, if the calculated vapor velocity $v_{g m j}\left(t_{m j}\right)$ based on $\varepsilon_{j}=1$ is less than $v_{f l o o d}$, the presoure drop imposed on the system is not sufficient to sustain the complete roughness of the interface. Therefore, in this case the film should be in the transient flooding state with changing roughness (see Fig. 8). Under this condition the vapor velocity is taken as

$$
v_{\text {gmj }}=v_{\text {flood }} \cdot
$$
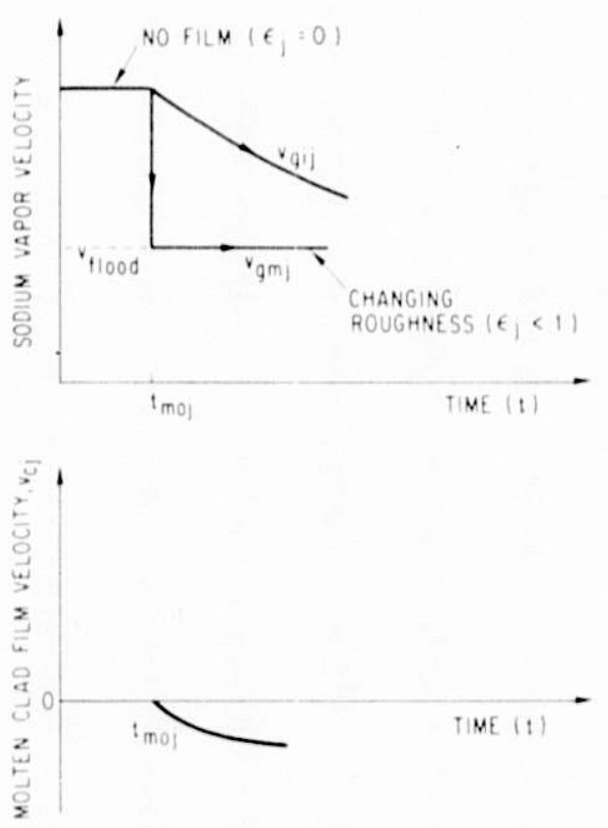

Fig. 8. Initial Transient Flooding.

(ANL Neg. No. 900-76-649.)

During the transient flooding state,

interfacial roughness adjusts to the available pressure gradient; hence $\varepsilon_{j}$ will be considered as a variable with the fixed vapor velocity in the vapormomentum equation (7). Consequently, by denoting the inlet vapor velocity with assumed intact subassembly geometries as $\mathrm{v}_{\mathrm{gioj}}$, we have

$$
\varepsilon_{j}=\left\{\left(\frac{\Delta p_{m}}{l_{m}}-\rho_{g} g\right) \frac{l_{o}}{\left(\Delta p-\rho_{g} g l_{o}\right)}\left[\frac{v_{g i o j}}{v_{g m j}}\right]^{1.75}-1\right\} \frac{\alpha_{o j} l_{m}}{75\left(1-\alpha_{o j}\right)}, \lambda_{j},
$$

which applies for $\varepsilon_{j} \geq 0$. If $\varepsilon_{j}$ calculated from the above expression becomes negative, then a complete deflooding has occurred and $\varepsilon_{j}$ should be taken as zero in the vapor- and liquid-momentum equations. 
A similar transient occurs after the flow reversal following the initial upward motion. Instead of imposing a condition leading to deflooding, it has been assumed that the rough interfacial friction factor can be used up to the flow reversal. Thus the deflooding point is automatically predicted by solving the equations of motion for the vapor and molten film. After the flow reversal the roughness of the interface decreases gradually and the momentum exchange between the phases will be reduced. Therefore we have

$$
\varepsilon_{j}=1 \quad \text { for } t<t_{r j} .
$$

For $t>t_{r j}$ the deflooding parameter is calculated from Eq. (37) by using $v_{g m j}=v_{g m j}\left(t_{r j}\right)$.

The above-described deflooding and transient-flooding model is an approximate dynamical model. Analyses of the flooding phenomena in rapid transient conditions is almost nonexistent in the literature. Even under quasi-steadystate conditions, there are some uncertainties and conflicting results among existing flooding correlations when they are applied to liquid metals. ${ }^{3}$ In view of the present state of the art in two-phase flow dynamics, the method used in the present analysis for the deflooding process seems far better than using the experimental flooding correlations, since it takes account of the liquid inertia.

\section{Clad Slumping}

Slumping of the molten-clad film into the sodium two-phase mixture or sodium liquid is a fairly complicated phenomenon. During the process, sodium boiling and molten-clad quenching and solidification take place. Due to the multichannel effects the slumping of molten clad may not occur uniformly. This will lead to the formation of a partial blockage in the subassembly at the bottom of the fuel region, and the flow diversion of the molten clad from 
the blocked channel to other channels becomes possible. The real situation may be further complicated if the upper blockage from the solidified molten clad is nonexistent or incomplete and the sodium chugging still exists in this stage of the accident.

When the molten clad slumps into the liquid sodium (see Fig. 9), the wall conduction and convective boiling heat transfer removes the stored energy in the film leading to the solidification. The previous analysis on the upper freezing shows that the time scale of complete blockage formation by the wall conduction alone is of the order of $0.2 \mathrm{~s}$. The solidification time can be further shortened by the sodium convection at the outside of the

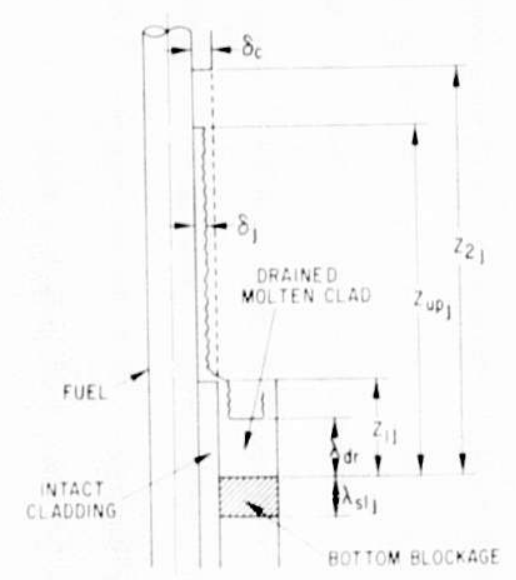

Fig. 9. Clad Slumping. (ANL Neg. No. 900-7668, Rev. 1.)

film. However, because of the very short time scale involved in the bottom freezing process, conditions following the slumping will be insensitive to the details of the analysis on the blockage formation. From this point of view, a rather simple solidification model based on the conduction heat transfer to the cold wall alone has been used. Furthermore, any convection effect on the molten-clad film caused by the liquid sodium was neglected during the freezing process, and only the effect of the flow diversion of the molten clad due to a partial subassembly blockage has been considered.

By analogy to the upper freezing, the bottom solidified layer of cladding material can be given by

$$
\delta_{f r j}^{\prime}=2 A^{\prime} \sqrt{k_{c}\left(t-t_{s \ell j}\right)},
$$

where 


$$
A^{\prime} \doteq \frac{\ln \left[C_{C}\left(T_{C p}-T_{i}\right) / L_{C}\right]+1.09}{3.28}
$$

and

$$
\mathrm{Z}_{\mathrm{down}}\left(\mathrm{t}_{\mathrm{slj}}\right)=0
$$

Therefore $t_{s l j}$ denotes the starting time of slumping of molten clad into liquid sodium at the lower end of the heated section in the $j$ th channel. The initial temperature of the cold cladding was taken as the incoming subcooled liquid-sodium temperature $\mathrm{T}_{i}$ instead of sodium saturation temperature $\mathrm{T}_{\text {sat }}$, in order to take into account the convection effects in the slumping region. The time required to form a complete blockage for the $j$ th channel by freezing of the slumped clad is

$$
t_{b l j}-t_{s l j} \equiv \Delta t_{s l j}=\left(\frac{D_{o j}}{8 A^{1}}\right)^{2} \frac{1}{k_{c}} .
$$

By simply extending the film-motion model described in the previous sections and by neglecting any effect caused by slumping and freezing, the length of the bottom blockage is given by

$$
\lambda_{s \ell j}=-\int_{t_{s \ell j}}^{t} v_{c j} d t=-z_{d o w n j} .
$$

This equation is applicable to the channel which forms the bottom blockage from its own molten clad.

For convenience, let us denote the first channel to slump into the cold sodium as the kth channel and other channels as ith channel. Then at $t=t_{b \ell k}$ the first channel is plugged by solidified clad. If $z_{\text {downi }}\left(t_{b l k}\right) \leq 0$, then this ith channel is also considered to form the bottom blockage with its own molten clad. However, if $z_{\text {downi }}\left(t_{b \ell k}\right)>0$, then it becomes possible for the 
kth-channel molten clad to divert into the channel, where its clad film is yet to slump. For this blockage formation due to the interconnected-channel effect, we have $t_{s \ell i}=t_{b l k}$ and

$$
\lambda_{s \ell i}=-\int_{t_{b \ell k}}^{t} v_{c k} d t \text {. }
$$

The time of the total bottom blockage formation is defined by $t_{b \ell} \equiv$ $t_{b \ell k}+\max \left[\Delta t_{s \ell i}\right]$. At $t=t_{b \ell}$ all the vapor velocities becomes zero due to the complete blockage formation. Similarly, the time of first slumping is defined by $t_{s l}=t_{s l k}$. After the total subassembly is blocked at the bottom, the molten-clad films simply drain ard accumulate over the blockage; thus we have from Eq. (12)

$$
\frac{1}{\lambda_{j}} \rho_{c} \frac{d\left(v_{c j} \lambda_{j}\right)}{d t}=-\frac{2}{3}\left(\rho_{c}-\rho_{g}\right) g-\frac{2 \mu_{c} v_{c j}}{\delta_{c}^{2}}\left(\frac{\delta_{c}}{\delta_{j}}\right)^{2} .
$$

The mass used for blockage formation from ith channel, $M_{b l i}$, is given by

$$
M_{b \ell i}=-\int_{t_{s \ell i}}^{t} b_{l i} 2 \pi R_{F} n_{p i n i} \delta_{i} v_{c i} d t
$$

if the blockage is formed with its own clad; otherwise $M_{b \ell i}=0$, and we have used

$$
\delta_{i}=\left[\lambda_{i}\left(t_{s l i}\right) \delta_{c}-\lambda_{f r i} \delta_{i}\left(t_{f r i}\right)\right] / \lambda_{m i}\left(t_{s l i}\right)
$$

For the kth channel some additional steel which is used to block other channels should be also added to $M_{b l k}$. Then at the blockage completion the film thickness of $j$ th channel is given by

$$
\delta_{j}=\frac{\lambda_{j}\left(t_{b \ell}\right) \delta_{c}-\lambda_{f r j} \delta_{i}\left(t_{f r j}\right)-M_{b \ell j} /\left(2 \pi R_{F} n_{p i n j}\right)}{\lambda_{m j}\left(t_{b l}\right)} .
$$


By solving the liquid-momentum equation (46), the level of drained molten clad, $\lambda_{\mathrm{dr}}$, can be easily determined from a simple mass balance. The fraction of the total area $A_{j}$ available for the $j$ th channel is denoted by $\alpha_{d r j}$, where $\alpha_{d r j}$ can be determined from purely geometrical relations between $z_{1 j}, z_{2 j}$, $z_{\text {upj }}, z_{\text {downj }}$, and $\lambda_{\mathrm{dr}}$. Then the area in which the molten clad accumulates is given by $A_{d r}=\sum A_{j}{ }_{d r j}$. Now we define a parameter $C_{d r j}$ such that

$$
\left\{\begin{array}{lll}
C_{\mathrm{drj}}=1 & \text { if } & Z_{\mathrm{downj}} \leq \lambda_{\mathrm{dr}} \\
\mathrm{C}_{\mathrm{drj}}=0 & \text { if } & Z_{\text {down } \mathrm{j}}>\lambda_{\mathrm{dr}}
\end{array}\right.
$$

In terms of the above variables, the level of the drained molten clad is given by

$$
A_{d r} \frac{d \lambda d r}{d t}=-\sum 2 \pi R_{F} n_{p i n j} C_{d r j} v_{c j}{ }^{\delta} j\left[1+\frac{\alpha_{w r}{ }^{\delta} c}{\delta_{j}}\right],
$$

where $\alpha_{w r}$ is the ratio of area of the wire wrap melted to that of the intact cladding. If the mass of the wire drains with the clad film, then $\alpha_{w r}=$ $\mathrm{D}_{\mathrm{Wr}}^{2} /\left[4\left(\mathrm{R}_{\mathrm{C}}{ }^{2}-\mathrm{R}_{\mathrm{F}}{ }^{2}\right)\right]$. in the above equation for $\lambda_{\mathrm{dr}}, \mathrm{C}_{\mathrm{drj}}$ becomes zero when the available molten mass of the $j$ th channel completely drains down. This limit can be obtained from a mass balance in the following manner. The volume of molten-clad mass drained from the $\mathrm{jth}$ channel below $\lambda_{\mathrm{dr}}$ per perimeter is given by

$$
v_{d r j}=\delta_{j}\left[1+\frac{{ }^{\alpha}{ }_{w r} \delta}{\delta_{j}}\right]\left\{\int_{t_{b \ell}}^{t} c_{d r j}\left[\frac{d \lambda d r}{d t}-v_{c j}\right] d t\right\} .
$$

Then under the conditions

$$
\left\{\begin{array}{l}
\lambda_{d r}<z_{1 j} \text { and } \\
v_{d r j} \geq \lambda_{j} \delta_{c}\left(1+\alpha_{w r}\right)-\frac{M_{b l j}}{2 \pi R_{F} n_{p i n j}}-\delta_{f r j} \lambda_{f r j}
\end{array}\right.
$$


or

$$
\left\{\begin{array}{l}
\lambda_{\mathrm{dr}} \geq \mathrm{Z}_{1 j} \text { and } \\
\mathrm{V}_{\mathrm{dr} i} \geq\left(\mathrm{Z}_{2 j}-\lambda_{\mathrm{dr}}\right) \delta_{\mathrm{c}}\left(1+\alpha_{w r}\right)-\frac{M_{b \ell j}}{2 \pi R_{F} n_{p i n j}}-\delta_{f r j} \lambda_{f r j}
\end{array}\right.
$$

we have

$$
\mathrm{C}_{\mathrm{drj}}=0
$$

If the above limit occurs for all the channels, we have $\mathrm{d} \lambda \mathrm{dr} / \mathrm{dt}=0$, and the motions of the molten-clad film in the subassembly are terminated. Beyond this limit there is no more consistent motion of the molten-clad film, since the film has completely drained down. After the termination of the $\mathrm{film}$ motion, it is still possible that newly melted clad moves down along the pins, if some intact cladding exists above the accumulated molten clad. However, it is more likely that in this stage molten clad rolls down as droplets along the solid surface.

Since it is expected that most of the clad has melted and drained down at the end of the film motion, the present analysis is terminated at this stage. It is noted that in the present analysis the motion of the fuel has not been considered. However, for larger reactors under unprotected loss-of-flow accidents, the complete melting through of fuel may occur prior to the clad slumping, since in these reactors the sodium voiding may have significant effects on the reactivity and power. In such cases, mixing of molten fuel and steel might occur before clad slumping, as proposed by Fauske. ${ }^{12}$ If this should happen, the structural integrity of the fuel pin is lost completely, and the geometry of the flow is quite different from that cussidered in the analysis. Therefore, the onset of fuel motion caused by fuel melting is also 
a practical termination to the clad relocation that occurs in the manner considered in the present analysis. 


\section{SAMPLE CALCULATIONS AND DISCUSSION}

Based on the present multichannel clad-relocation model, a computer program has been developed and several sample calculations have been made. The first example considered here is the simulation of the R-series 7-pin in-pile tests in the TREAT reactor. ${ }^{13}$ The R-4 and R-5 tests were run under the basically same loss-of-flow conditions with the 7-pin test sections. The difference between these two tests was the timing of the power termination. The purpose of the R-4 test was to obtain data for an integrated sequence of events up to and including complete meltdown, whereas in the R-5 test the power was terminated prior to fuel melting in order to preserve evidence of molten-clad relocation.

The dimensions of the fuel pins were identical to those of the FFTF, and the cross section of the 7-pin test assembly is shown in Fig. 10. The test fuel power was kept constant at

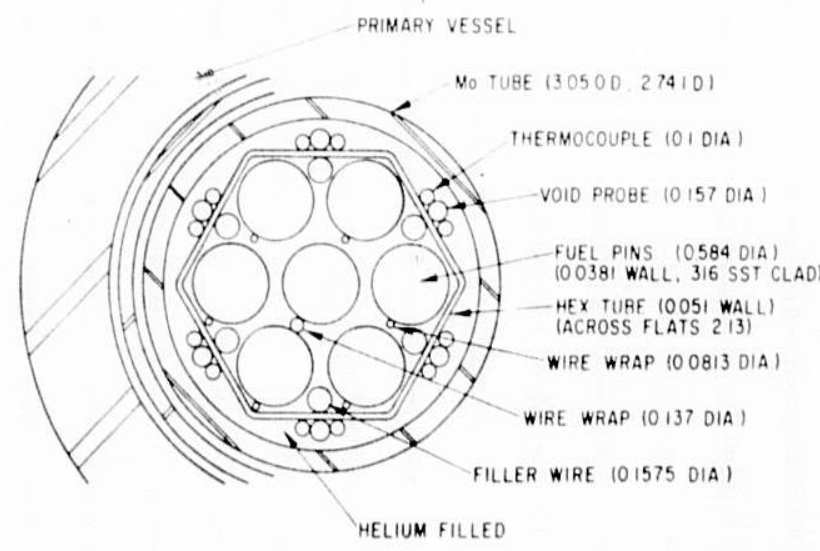

ALL DIMENSIONS IN cm

Fig. 10. Cross Section of 7-pin Test Assembly.

(ANL Neg. No. 900-75-73, Rev. 1.) terior subchannels.

The key times of important events beyond sodium boiling in these tests ${ }^{13}$ are shown in Table I. 
TABLE I. TIMES ( $\mathbf{s}$ ) OF EXPERIMENT SEQUENCES

\begin{tabular}{lcc} 
& $\underline{\mathrm{R}-4}$ & $\underline{\mathrm{R}-5}$ \\
Local Boiling & 13.25 & $12.5-13.5$ \\
Inlet Flow Reversal & 14.87 & 14.56 \\
Dryout Indication & 15.2 & 14.8 \\
Clad Failure & 16 & 15.7 \\
Probable Hexcan Failure & 18 & 17.85 \\
Power Down & 25 & 19 \\
\hline
\end{tabular}

This indicates that it takes about $1.9 \mathrm{~s}$ from the inception of boiling to dryout and $1 \mathrm{~s}$ from dryout to clad failure. The posttest radiographs of the test sections are shown in Fig. 11, which indicate the extent of the clad
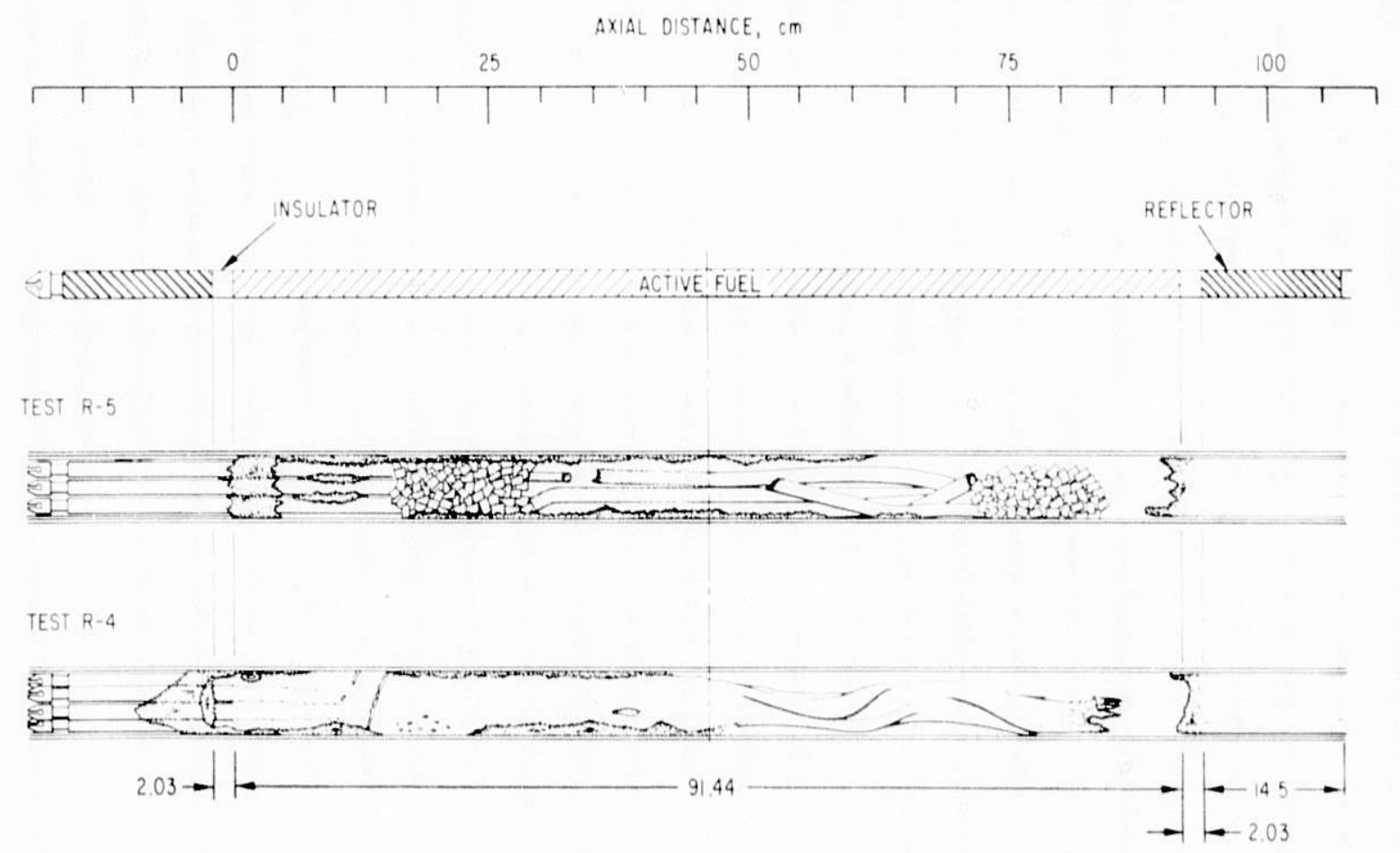

Fig. 11. Post-transient Radiographs for $R-4$ and $R-5$ Loss-of-flow Tests. (ANL Neg. No. 900-75-67, Rev. 1.)

relocation in tests $\mathrm{R}-4$ and 5 . The radiographs may be interpreted to indicate that a minimal plug was formed at the exit of the heated zone and that a significant amount of clad material drained prior to the fuel melting. 
The input data $Z_{1 j}(t)$ and $z_{2 j}(t)$ for the present clad-motion model have been obtained from the simple thermal transient analysis for fuel pins. ${ }^{1}, 2$ The total pressure drop in the voided section was taken as the hydrostatic head of the liquid sodium. The inlet temperature $\mathrm{T}_{i}$ was $327^{\circ} \mathrm{C}$, and the liquid sodium density was $0.873 \mathrm{~g} / \mathrm{cm}^{3}$. The fuel-pin geometry was that of the FFTF. Thus $\mathrm{R}_{\mathrm{F}}=0.254 \mathrm{~cm}, \mathrm{R}_{\mathrm{C}}=0.292 \mathrm{~cm}, l_{\mathrm{O}}=214.6 \mathrm{~cm}, l_{\mathrm{F}}=91.44 \mathrm{~cm}, l_{\text {ins }}=2.03$ $\mathrm{cm}$, and $\ell_{\text {ref }}=14.5 \mathrm{~cm}$ were used. The channel dimensions of the 7-pin test are given in Fig. 10. The hexagonal duct which encased the seven fuel pins was $2.13 \mathrm{~cm}$ across the flats with a $0.05-\mathrm{cm}$ wall thickness. In the present calculation the cross section was divided into two ringwise channels. Thus by denoting the central channel and the wall channel by a subscript 1 and 2, respectively, the standard hydraulic diameter was $\mathrm{D}_{\mathrm{o} 1}=0.324 \mathrm{~cm}$ and $\mathrm{D}_{\mathrm{o} 2}=$ $0.217 \mathrm{~cm}$. The area fractions of the intact clad in the flow areas with channels 1 and 2 stripped fuel pins, $1-\alpha_{0 j}, 0.2726$ and 0.2079 , respectively. The sodium saturation temperature $\mathrm{T}_{\text {sat }}$ was $899^{\circ} \mathrm{C}$, and the clad melting temperature $\mathrm{T}_{\mathrm{CP}}$ was $1427^{\circ} \mathrm{C}$.

During the molten-clad motion, the steel properties corresponding to the liquid state at melting were used; thus $\mu_{c}=0.065 \mathrm{~g} / \mathrm{cm}-\mathrm{s}$ and $\rho_{c}=7.36 \mathrm{~g} / \mathrm{cm}^{3}$. On the other hand, the sodium-vapor properties were calculated at the saturation temperature; hence $\rho_{g}=3.12 \times 10^{-4} \mathrm{~g} / \mathrm{cm}^{3}$ and $\mu_{\mathrm{g}}=1.98 \times 10^{-4} \mathrm{~g} / \mathrm{cm}-\mathrm{s}$.

The results of the sample calculation under the above conditions are shown in Figs. 12 and 13. The input data were those for the $R-5$ test case; however, the conditions for the $\mathrm{R}-4$ test case were considerably similar to those used in the calculation. The fuel-pin thermal transient and the melting of fuel and cladding materials were calculated from the simple mode ${ }^{2}$ based on the integral model. The thermo-hydraulics of sodium flows in a multichannel geometry were analyzed by using a forced-flow diversion model ${ }^{9}$ up to the time of boiling initiation. 


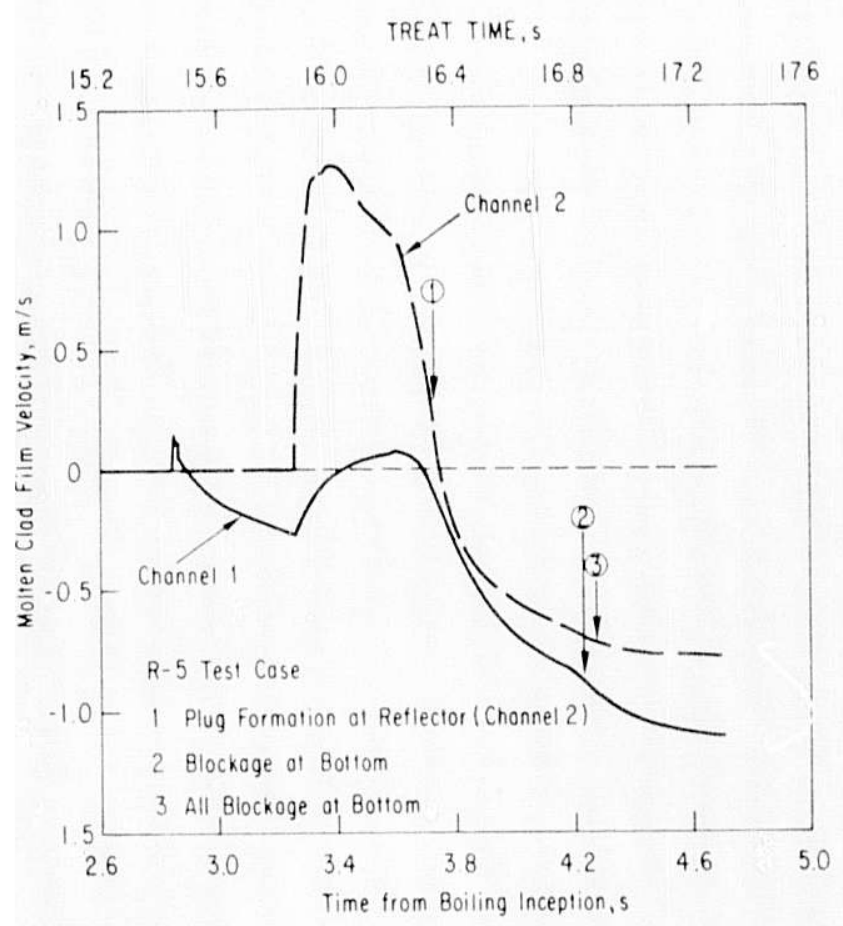

Fig. 12. Prediction of Molten-clad Velocity for Test $R-5$ Case with 2-channel Model Based on a simple voiding Model.

(ANL Neg. No. 900-78-771.)

Fig. 13. Prediction of Moltenclad Motion for Test R-5 Case with 2channel Model. (ANL Neg. No. 900-78774.)

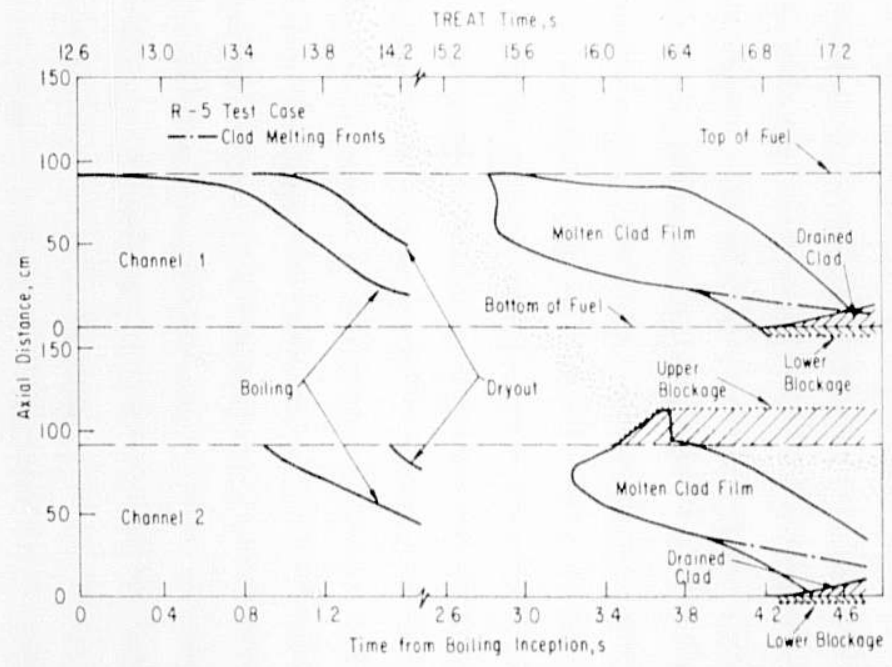

The sodium boiling and occurrences of dryout in a multichannel geometry are quite complicated phenomena, and a method to predict these phenomena is not well established. However, in the present multichannel clad-motion model, the extent of the dryout region as a function of time for each channel should be supplied for the fuel-pin-melting model in order to calculate the cladmelting boundaries $z_{1 j}$ and $z_{2 j}$. Therefore, as a first estimate, a simple calculation procedure has been adopted in the absence of a more complete model. It is basically an extension of the heat-capacity model ${ }^{1}$ with the 
assumption that the complete liquid sodium bypasses the boiling subchannels. This assumption is based on the observation that for a forced-convection system with a high heat flux and with a very large ratio of liquid to vapor density, the pressure drop increases considerably by going from a subcooledliquid flow condition to a two-phase flow condition. Therefore, once a certain channel starts to boil, most of the incoming liquid sodium should be diverted into other nonboiling channels in order to equalize the pressure gradient. Furthermore, it has been assumed that the flow reversal follows immediately after all channels have reached the boiling condition.

Under the R-5 test condition, both the single-channel case* and twochannel case have been studied by using the above sodium-voiding model in addition to the previous single-channel calculation ${ }^{3}$ which was based on the dryout prediction made by SAS code.

The flow coastdown started at $7.9 \mathrm{~s}$ in the TREAT transient time. The test-section power was kept at $29 \mathrm{~kW} / \mathrm{pin}$ until the power termination at $19 \mathrm{~s}$. In the multichannel calculation the inception of sodium boiling occurred at 12.6 $\mathrm{s}$ in the central channel (channe1 1), and the clad motion started at $2.8 \mathrm{~s}$ after the boiling inception in the same channel. The timings of various transients in the wall channel (channe1 2) were slightly delayed due to the lower coolant temperature. Hence, the boiling inception occurred at $13.5 \mathrm{~s}$ in the channel 2, and the flow reversal immediately followed. The dryout of the cladding surface started from the vicinity of the top of the fuel section and propagated downward. The predicted dryout initiation time is $13.5 \mathrm{~s}$ for the central channel and $14.1 \mathrm{~s}$ for the wall channel.

It can be seen from Fig. 12 that the clad motion started at $2.8 \mathrm{~s}$ (channel. 1) and at $3.2 \mathrm{~s}$ (channel 2) after the initiation of sodium boiling,

* The sodium-voiding model used for the single-channel case is the simplified form of the resent voiding model by eliminating the bypass effect. 
whereas in R-4 and R-5 tests the times were 2.75 and $2.2-3.2 \mathrm{sec}$, respectively. The measurement of the failure of the fuel-pin clad was based upon flowmeter response to the release of fill gas from the gas plenum. Therefore, it is expected that the experimental clad failure occurred just prior to the initiation of clad motion. From this consideration it can be said that the simple thermal transient analysis predicts the clad-melting time from the boiling initiation within reasonable accuracy. However, it is noted that the prediction of the boiling inception by considering the two-dimensional effects is about 1 s earlier than the experimental data or the one-dimensional calculation. This point will be discussed later in relation to the one-dimensional mode1.

In view of Fig. 12, the initial motion of the molten clad in the central (hotter) subchannels was upward; however, the extend of the upward motion was severely limited due to the sodium-vapor diversion to peripheral (colder) subchannels. It was indicated that in this early stage the molten-clad film was not completely rough-wavy, and therefore it was in the deflooding process. The flow reversal occurred to the molten clad in channel 1 at $2.9 \mathrm{~s}$ from boiling inception.

At approximately $3.2 \mathrm{~s}$ from boiling inception, the cladding material in the wall channel started to move. Since in this stage the bypass effect of sodium vapor was nonexistent, the molten clad in channel 2 moved much the same as predicted by the one-dimensional model (see Figs. 12 and 14). The film was predicted to reach the top of the heated section within $0.2 \mathrm{~s}$ from the initiation of clad motion in this colder channel, and freezing occurred both at the upper insulator and reflector sections. A complete blockage in channel 2 was formed with in $0.5 \mathrm{~s}$ from the initiation of motion, and the flow reversal followed immediately. 
In the central channel the flow reversal from downward to upward occurred when clad motion started in the wall channel. This was because the part of the sodium vapor initially diverted to the wall channel was redirected back to the central channel due to the increase in the hydraulic resistance in the wall channel. However, as can be seen from Fig. 12, the overall upward motion in the central channel is considerably less than that in the wall channel. The freezing in the central channel is very limited, and a complete blockage has never formed in this part. Consequently, the upper blockage for the subassembly should be a partial blockage, and the most of the frozen mass should be located at the peripheral channel.

The downward flow reversal occurred almost simultaneously in channels 1 and 2 after channel 2 was completely plugged. After this time, motion of the molten clad became increasingly coherent and basically reduced to a downward one-dimensional behavior. This can be seen from Figs. 12 and 14. It is noted that the vapor flow continued up to the time of the lower blockage formation by the draining molten clad. At $4.2 \mathrm{~s}$ after boiling initiation, the molten clad in the central channel slumped into the liquid sodium. The lower blockage was completed within $0.2 \mathrm{~s}$, and the extent of the initial flow blockage was relatively small (no more than $4 \mathrm{~cm}$ ). Following the formation of the bottom plug, the draining molten clad from both the central and wall channels accumulated over the blockage up to about $20 \mathrm{~cm}$. At $4.9 \mathrm{~s}$ from boiling initiation the films had completely drained down. Since in the test the power was terminated at $19.0 \mathrm{~s}$ in TREAT time, this accumulated molten clad should have solidified in the position.

The posttest examination ${ }^{14}$ showed a relatively small partial blockage $(\sim 1 \mathrm{~cm})$ at the reflector section (see Fig. 11), which was consistent with the above calculations. In addition to uncertainties in the test-bundle pressure 
drop at the time of clad melting and in the prediction of voiding incoherency, any upper blockage formed in the test could have been remelted due to axial conduction or radiant heat transfer, and might have been redistributed more uniformly across the test section at the reflector section. The magnitude of the lower blockage, as well as the qualitative prediction of the upper blockage, are in good agreement with the posttest results. The overall physical behavior predicted by the model is quite satisfactory.

Several additional observations can be made by comparing the twodimensional behavior (see Figs. 12 and 13) with the one-dimensional behavior. Because of the higher initial coolant temperature and heat input, the central channel reaches the boiling condition (at $t=12.6 \mathrm{~s})$ earlier than $(t=13.9$ s) predicted from the one-dimensional model, based on the averaged heat input and averaged coolant temperature across the test section. Once the central channel starts to boil, most of the liquid sodium in the central channel is diverted with the near-saturation enthalpy to the wall channel at the boiling section. This diversion of the higher-enthalpy liquid to the colder channel heats the cladding and leads to earlier boiling initiation in the colder channel than if there were no flow diversions. Therefore, the net result of considering the incoherency effect is to speed up the voiding process. Furthermore, this may lead to earlier occurrences of dryout and clad motion. For the R-5 test case, the clad motion initiated at $15.4 \mathrm{~s}$ in the two-dimensional model and $16.1 \mathrm{~s}$ in the one-dimensional model. Hence, the difference in the initiation time of clad motion is almost $1 \mathrm{~s}$.

In the central channel the upward clad motion is milder than that predicted by the one-dimensional model, and the upper blockage in this channel is partial and minor, whereas in the wall channel the initial clad motion is strongly upward and molten clad penetrates further into the upper plenum than 
for the one-dimensional case. Hence, the upper blockage predicted by the multichannel model is a longer, but partial, blockage, and the sodium-vapor flow will not be stopped until the bottom blockage is completed.

In the sample calculation the sodium boiling and flow diversion in the multichannel geometry were analyzed by using the simple thermohydraulic model. Since a number of assumptions and simplifications have been used in the sodiumvoiding model, it is beneficial to compare it to a more established model. This was done by considering the one-dimensional case (see Figs. 14 and 15).

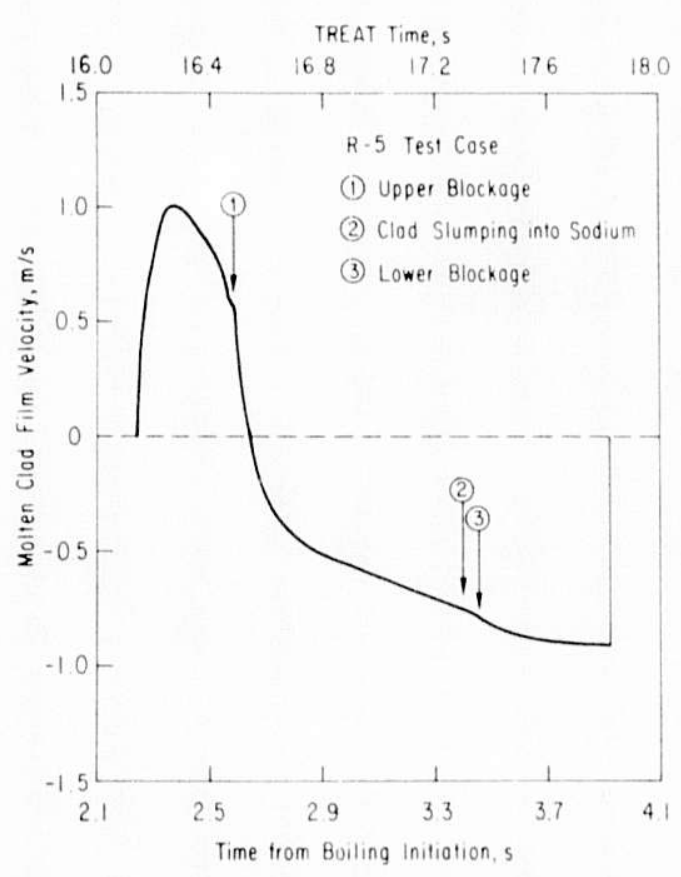

Fig. 14. Prediction of Moltenclad Velocity for Test R-5 Case with Singlechannel Model Based on Simple Voiding Model. (ANL Neg. No. 900-78-777.)

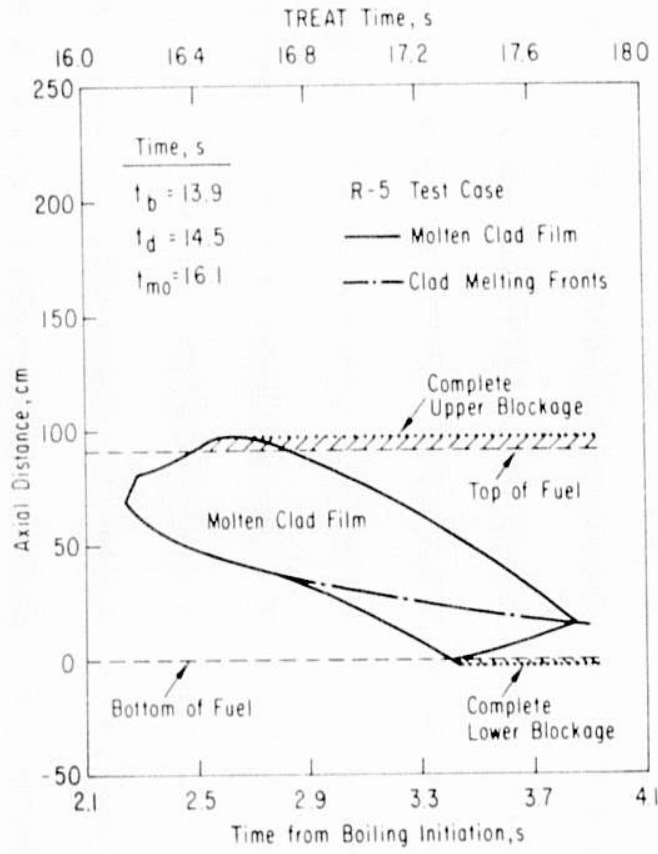

Fig. 15. Prediction of Moltenclad Motion for R-5 Test Case with Single-channel Model Based on Simple Voiding Model.

(ANL Neg. No. 900-78-779.)

The comparison of predictions of the clad motion based on the present voiding model and that based on the SAS-code dryout timing is given in Figs. 16 and 17. The predictions of the time $t_{b}$ of initiation of the sodium boiling were within $0.1 \mathrm{~s}$, therefore the single-phase thermohydraulic analysis and the fuel-pin model used in the present model seem to be quite satisfactory. 


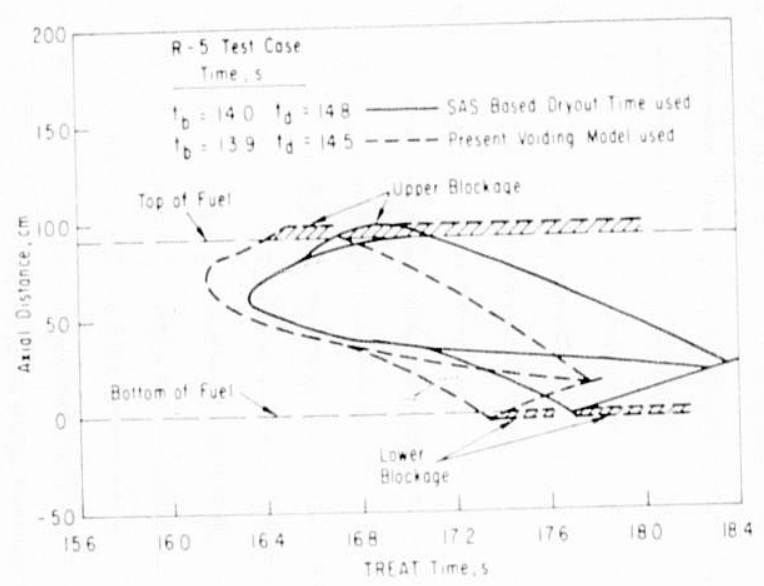

Fig. 16. Effect on the Voiding and Euel-pin Transient Model on the one-dimensional clad Motion.

(ANL Neg. No. 900-78-775.)

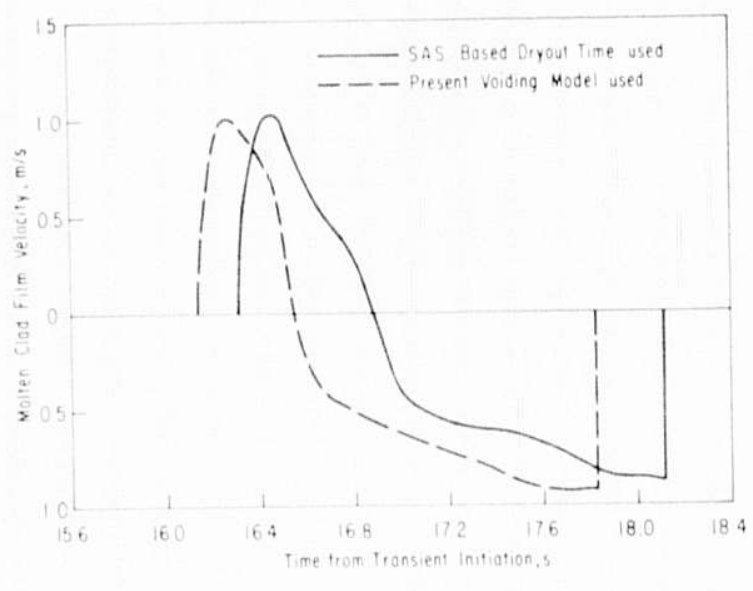

Eig. 17. Effect of the Voiting and Fuel-pin Transient Model on Molten-clad Velocity. (ANL Neg. No. 900-78-776.)

However, the assumption of immediate flow reversal after boiling initiation in the present model gives a dryout time $t_{d}$ about $0.3 \mathrm{~s}$ earlier than that otained based on the SAS voiding model. Consequently, the clad motion starts $0.3 \mathrm{~s}$ earlier when the present voiding model is used. Except for this difference in the timing of the initiation, overall behaviors of the molten clad are quite similar for these casses. This shows that the present voidin model can supply reasonably good input data for the clad-motion model in order to study overall behaviors of the molten clad and blockage formations.

The second example is a case with a power skew within an FFTF-type subassembly shown in Fig. 1. Three channels with identical area and hydraulic characteristics but with different power levels were considered. The hydrau1ic parameters were calculated from the subassembly average. The heat generation in a fuel pin was $\dot{q}_{1}=0.346 \mathrm{~kW} / \mathrm{cm}$ (or $10.55 \mathrm{~kW} / \mathrm{ft}$ ), $\dot{q}_{2}=0.9 \dot{q}_{1}$, and $\dot{q}_{3}=0.9 \dot{q}_{2}$.

The results of the sample calculation are shown in Figs. 18, 19, and 20. It can be seen that the initial clad notion for channel 1 is downward, and the 


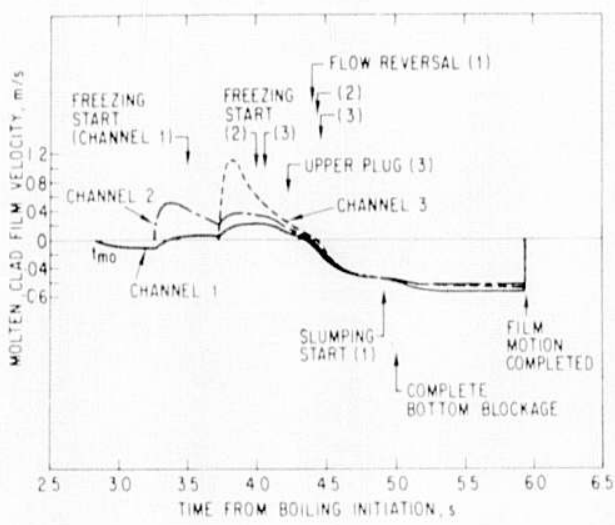

Fig. 18. Effect of Subassembly Incoherency Caused by Power Skew on Moltenclad Velocities Predicted by Using Three Computational Channels. (ANL Neg. No. 900-76-87.)

Fig. 19. Effect of Power Skew on Molten-clad Motion and Blockage Formation. (ANL Neg. No. 900-7689.)
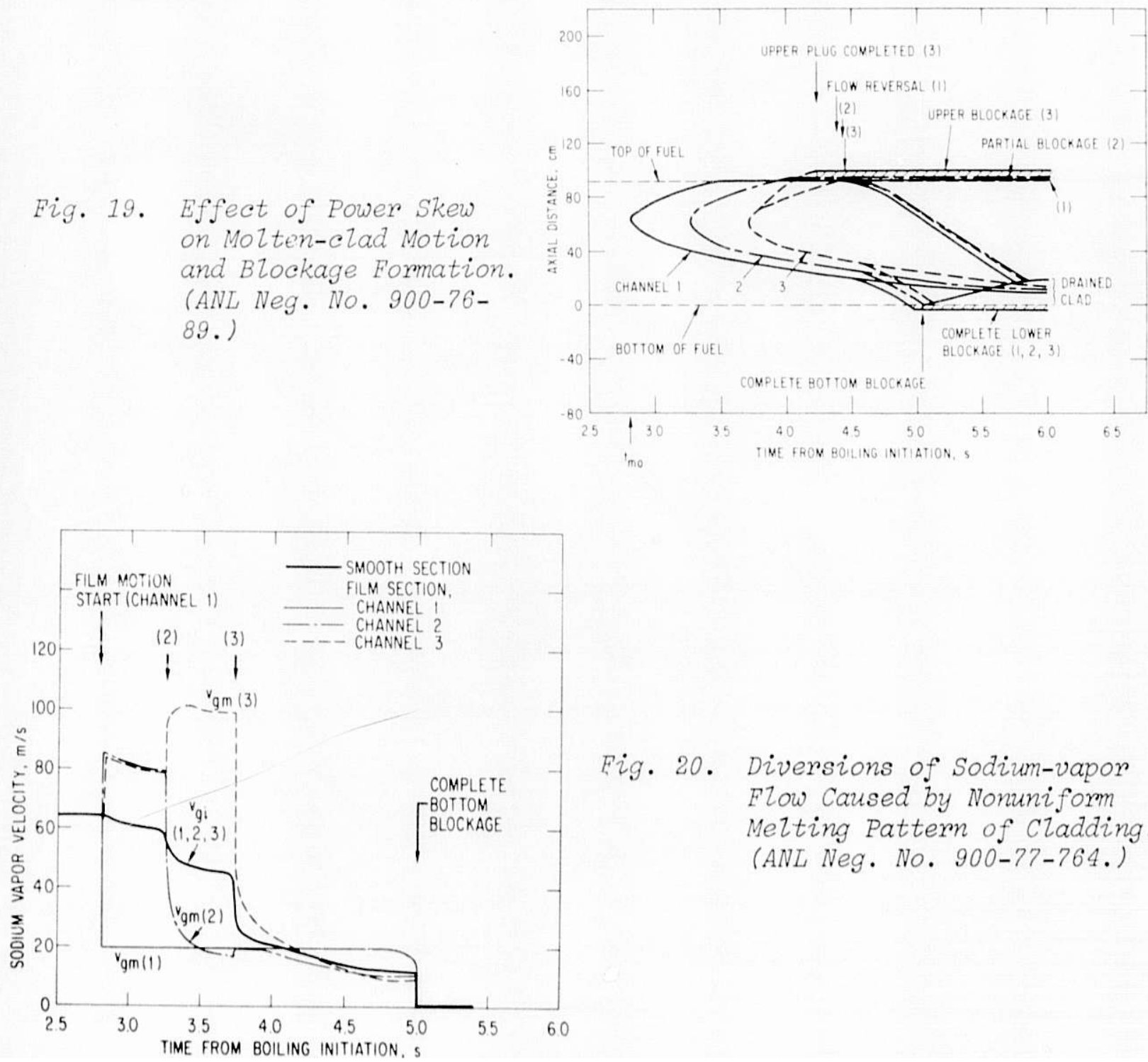

Fig. 20. Diversions of Sodium-vapor Flow Caused by Nonuniform Melting Pattern of Cladding. (ANL Neg. No. 900-77-764.) 
upward clad motion in channels 1 and 2 is severely limited due to the sodiumvapor diversion to the colder channels. On the other hand, molten clad in channe1 3 moves much the same as predicted by the one-dimensional model. Freezing occurred in ali three channels, but the blockages formed in channel 1 and 2 were not complete. After the completion of the blockage in channel 3 , the motions of clad in three channels become increasingly coherent, as shown in Fig. 18 .

The sodium-vapor diversions due to the initiations of the clad motion in various channels are shown in Fig. 20. Furthermore, the decrease in the total vapor flux due to increased hydraulic resistances is clearly indicated by the plot of the inlet sodium velocity $\mathrm{v}_{\mathrm{gi}}$. The third example was the P3A test in which a subassembly having 37 full-1ength FFTF-type fuel pins was used. Coolant boiling dynamics and fuel pin dryout information for the experiment have been reported by Thompson et al. ${ }^{15}$ The specified time in seconds is from the initiation of the flow coastdown transient. The net boiling initiation was $8.8 \mathrm{~s}$ as detected by the acoustic detectors and flowmeters (see Fig. 21). Initial cladding failure was indicated by the passage of fission gas through the bundle outlet flowmeter at $10.8 \mathrm{~s}$ and the total loop

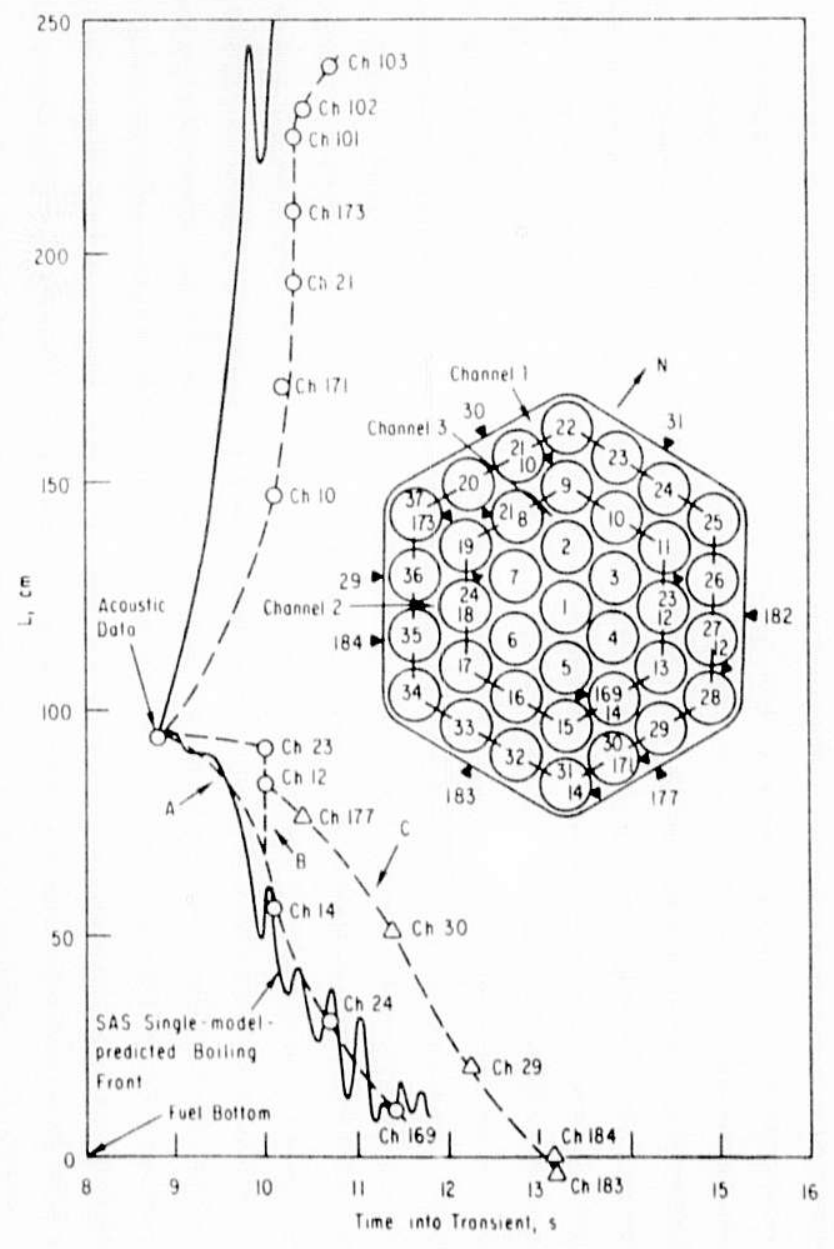

Fig. 21. Experimental Data on the Boiling Front Propagation for PBA Test. 15 
flowmeter at $11.6 \mathrm{~s}$. Extensive cladding melting occurred between $11.9 \mathrm{~s}$ and 12.2 $\mathrm{s}$ in the upper-half of the heated section. The molten cladding was carried upward by sodium vapor and started to form an upper cladding blockage at the top. The upper blockage appeared to be incomplete from the observation of both the outlet and the loop flowmeters. The fajlure pattern of several thermocouples indicated the downward motion of cladding around $13 \mathrm{~s}$. The inlet flowmeter showed oscillations around zero flow for a long period of time $(120 \mathrm{~s})$. This may indicate the disruption of the test section and therefore the final resolution of a bottom blockage cannot be made without the post-test examination of the subassembly.

As a part of the post-test analysis, calculations for predicting cladding relocation were performed using MULCLAD based on the multichannel model. Three ringwise computational channels have been used. The dryout curves based on the experimental observation have been used as input to the code. Figure 22 shows the location of the molten cladding predicted by the 3-channel model. The cladding motion initiated at $12.1 \mathrm{~s}$ in the central channels and the molten clad film moves upward over yet unmelted segments. The film reaches the top of the fuel at $12.5 \mathrm{~s}$ and starts to form a central blockage. The

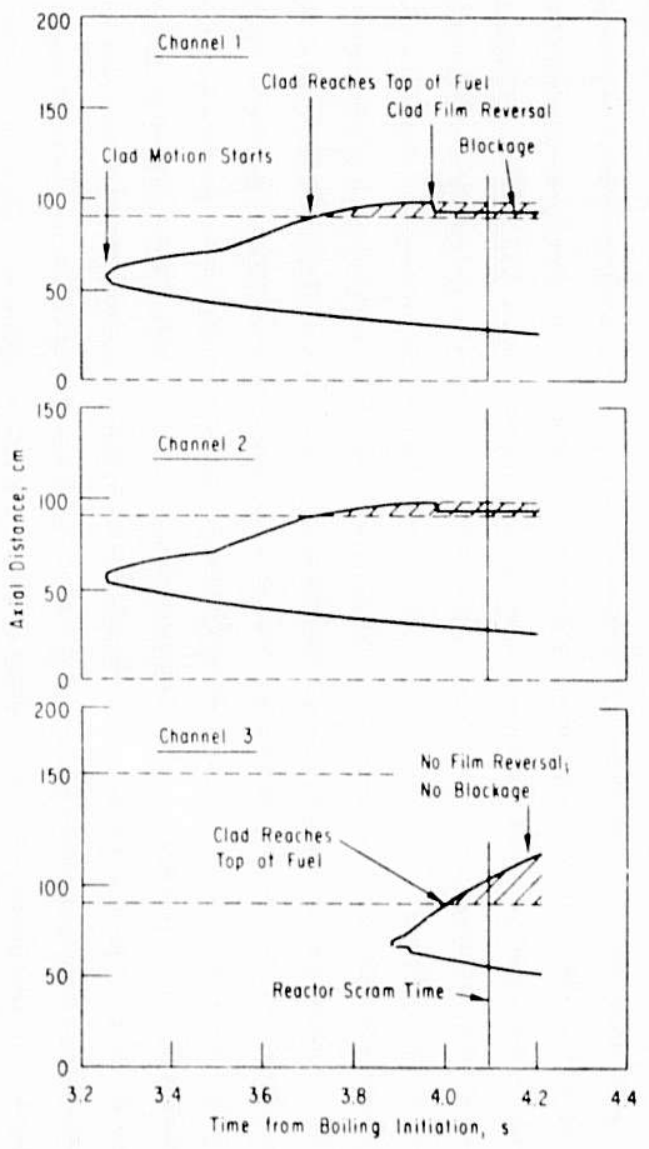

Fig. 22. Clad Motion Predictions from MULCLAD, for P3A Loss of Flow Experiment. (Net boiling initiation at 8.8 $s$ experiment time.) 
central blockage is completed in channel 1 and 2 at $12.8 \mathrm{~s}$. The extent of the molten steel penetration into upper plenum in the central channels is about 7 $\mathrm{cm}$. The molten cladding film in the wall channel (channel 3 ) reaches the top of the fuel pin at $12.8 \mathrm{~s}$ and starts to form an incomplete blockage. When the reactor is scrammed $(12.9 \mathrm{~s})$ the third channel has a $14 \mathrm{~cm}$ long $0.05 \mathrm{~cm}$ thick solidified steel in the upper plenum section. The top blockage, at the time of the reactor scram, is therefore an incomplete one. This agrees with the experimental observation based on flowneters. At the time of the reactor scram, clad velocities show a tendency to slow down. Possible draining occurred following the reactor scram.

Data from the presently available seven and 37-pin bundle experiments have been examined to study incoherency effects in clad motion in fuel bundles under loss of flow conditions. The observed incoherency is simulated with an analytical multi-channel clad motion model and predictions are compared with the experimental data. On the basis of this comparison it is found that, thermal incoherency in a subassembly accelerates initiation of voiding and clad motion, reduces mass of the central blockage in the bundle, may cause complete and longer blockage in the wall channel, has little effect on clad slumping in the absence of fuel motion. General agreement has been established between the test data and the analytical model. From this it is concluded that, incoherency effects can be successfully modeled to predict the resulting complex clad motion in multichannel pin bundles.

The above sample calculations clearly demonstrated the sound physical modeling of the complicated multidimensional behavior of molten clad during an 
unprotected loss-of-flow accident in LMFBRs. The stability of the model and the numerical scheme as well as the flexibility of the present multichannel clad motion model have been established. 


\section{ACKNOWLEDGMENTS}

The authors wish to express their sincere thanks to Dr. H. Fauske for helpful discussions concerning the effect of the incoherency sodium boiling, to Dr. D. Cho for his valuable comments on this study, and to Dr. T. Kuzay for his contributions related to SLSF P3A test comparison. 


\section{REFERENCES}

1. W. L. Chen, M. Ishii and M. A. Grolmes, Simple Fuel Pin Transient and Melting Model and Its Application to Thermo-Hydraulics in LMFBR Subassembly, ASME paper, 78-WA/HT-26, San Francisco, 1978.

2. W. L. Chen, M. Ishii, and M. A. Grolmes, Simple Heat Conduction Model with Phase Change for Reactor Fuel Pin, Nuc1. Sci. Eng. 60, 452 (1976).

3. M. Ishii, W. L. Chen, and M. A. Grolmes, Molten Clad Motion Model for Fust Reactor Loss-of-flow Accidents, Nuc1. Sci. Eng. 60, 435 (1976).

4. T. C. Chawla and H. K. Fauske, On the Incoherency in Subassembly Voiding in FTR and Its Possible Effect on the Loss-of-flow Accident Sequence, Trans. Am. Nuc1. Soc. 17, 285 (1973).

5. H. K. Fauske, Some Comments on Cladding and Early Fuel Relocation in LMFBR Core Dismuptive Accidents, Trans. Am. Nuc1. Soc. 21, 195, 322 (1975).

6. W. L. Chen, M. Ishii, and M. A. Grolmes, The Parametric Effects of Varied Channel Pressure Drop on the Molten-cladding Motion, ANL-76-84 (1976).

7. M. A. Grolmes, G. A. Lambert, and H. K. Fauske, Flooding Correzation for Sodium and Cladding Motion in Subassembly Voiding, Trans. Am. Nucl. Soc. 18, 209 (1974).

8. M. Ishii and M. A. Grolmes, Inception Criteria for Droplet Entrainment in Two-Phase Concurrent Film Flow, AIChE J. 21, 308 (1975).

9. W. L. Chen, M. A. Grolmes, and M. Ishii, A Simple Eorced Diversion Model for Study of Thermal-Hydranlic Transients in LMFBR Subassembly, Nuc1. Eng. Design, 45, 53 (1978).

10. G. F. Hewitt and N. S. Hall-Taylor, Anmiar Mwo-Phase Flow, Pergamon Press, New York (1970).

11. M. Ishii, T. C. Chawla, and N. Zuber, Constitutive Equation for Vapor Drift Velocity in Two-Phase Annular Flow, AIChE J. 22, 283 (1976).

12. H. K. Fauske, Boiling Fuel Steel Pool Characteristics in LMFBR HCDA Analysis, Trans. Am. Nuc1. Soc. 22, 386 (1975).

13. M. A. Grolmes, R. E. Holtz, B. W. Spencer, C. E. Miller, and N. A. Kramer, "R-series Loss-of-flow Safety Experiment in TREAT," Proc. of the Fast Reactor Safety Meeting, 1, 279, Beverly Hills, CA (1974).

14. C. E. Dickerman et al., Recent Results from TREAT Tests on Fuel, Cladding, and Coolant Motion, European Nuclear Conf. Trans., April 21-25, 1975, Paris, France.

15. D. H. Thompson et al., SLSF In-Reactor Experiment P3A - Interim Posttest Report, ANL-77-48 (1977). 